\title{
Aplicação do método AHP para auxílio à tomada de decisão do melhor tratamento para a borra oleosa gerada na indústria petroquímica
}

Wanderbeg Correia de Araujo Wanderbeg_ca@hotmail.com

Universidade Federal da Bahia (UFBA), Salvador, Bahia, Brasil

Isadora Fraga Gonçalves

Dorafraga@gmail.com

Salvador, Bahia, Brasil

Karla Patricia Oliveira Esquerre Karla Patricia Oliveira

Universidade Federal da Bahia (UFBA), Salvador, Bahia, Brasil

\begin{abstract}
RESUMO
O crescimento econômico e consequentemente o aumento de demanda por bens de consumo vem gerando um crescente problema relacionado ao gerenciamento de resíduos sólidos tanto no Brasil como no mundo. Aliado a isso, existe o fato de existirem poucos estudos quando se trata de resíduos sólidos industriais, principalmente os da indústria petroquimica. Esta realidade motivou este trabalho, que tem como objetivo principal a determinação da melhor alternativa para o tratamento da borra oleosa proveniente de uma empresa petroquímica. Para isto, foi utilizado o método de análise multi-critério AHP (Analytic Hierarchy Process), bastante utilizado em situações de tomadas de decisão onde é preciso levar em consideração a experiência das pessoas. Desta forma, para a realização da estrutura hierárquica das alternativas e critérios, foi necessária a presença de especialistas da área de meio ambiente da empresa. A hierarquização das alternativas de tratamento abordadas no trabalho produziu como resultado final a pirólise como sendo a alternativa mais adequada ao problema em questão, com $41 \%$ de preferência frente às alternativas citadas no trabalho. Com os resultados obtidos pelas matrizes de comparação do método, foi possível concluir que há um aumento da preocupação por parte das empresas em relação ao gerenciamento de resíduos e seus possíveis impactos ao meio ambiente. Outra conclusão, porém, é que no Brasil ainda há a necessidade de crescer com relação à pesquisa e desenvolvimento na área de gerenciamento de resíduos sólidos industriais para que haja mais opções de tratamento e que estas sejam mais acessíveis.
\end{abstract}

PALAVRAS-CHAVE: Método AHP. Resíduos sólidos. Borra oleosa. Tecnologia de tratamento 


\section{INTRODUÇÃO}

A problemática dos resíduos sólidos no Brasil e no mundo é um tema muito abordado atualmente. $\mathrm{O}$ crescimento da economia e o consequente aumento da demanda por produtos de consumo vem gerando um aumento significativo na geração de resíduos. Com esse aumento, uma questão importante passa a se fazer presente: $O$ que fazer com esses resíduos? Quando falamos então de resíduos industriais a questão fica ainda mais complexa devido ao seu grau de periculosidade.

Os resíduos de origem oleosa, muitas vezes presentes em indústrias petroquímicas, são considerados perigosos e com um potencial alto de contaminação do ar, solo e corpos hídricos. Dentre eles, a borra oleosa recebe especial atenção de acordo com Cerqueira (2011), visto que esta se caracteriza como resíduo perigoso, podendo ter em sua composição compostos tóxicos e carcinogênicos que trazem malefícios não só ao meio ambiente como à população também. Dessa forma, se faz necessária uma análise meticulosa da escolha para a destinação e/ou tratamento do mesmo, de forma que o resíduo não represente mais um problema à saúde e ao meio ambiente.

Atualmente existem diversos métodos de análise de decisão multicritério que auxiliam na tomada da decisão. Nesse contexto, o método de análise hierárquica (AHP) se mostra como um método promissor. Por ser um método que leva em consideração o conhecimento e experiência de especialistas, o AHP tem sido bastante utilizado em problemas de gerenciamento de resíduos, que geralmente são problemas complexos e com escolhas de certa forma subjetivas. De acordo com Frasson (2011), a ferramenta permite a modelagem do problema em uma estrutura hierárquica, tendo como resultado a alternativa mais indicada baseada nos critérios escolhidos para a avaliação.

Portanto, o artigo tem como objetivo central utilizar o método AHP para apoiar na tomada de decisão para a determinação da melhor alternativa de tratamento/destinação do resíduo da borra oleosa de uma indústria petroquímica.

Além desta introdução, o estudo está dividido em outras quatro partes. A seção dois apresenta o referencial teórico da pesquisa, no qual se discute a problemática das indústrias e os resíduos sólidos no meio ambiente, a indústria petroquímica e o problema da borra oleosa, bem como discutir as principais formas de tratamento/destinação desse resíduo. Além disso, nessa seção, apresentou-se o método AHP. Na terceira seção expõe os procedimentos metodológicos que foram empregados na pesquisa, caracterizando o tipo da pesquisa, a coleta dos dados, bem como definir os critérios e alternativas para tomada de decisão pelos especialistas na empresa estudada.

A quarta seção apresenta os resultados e a discussão da aplicação do método AHP na pesquisa. Por fim, na quinta seção, são feitas as conclusões finais do trabalho, apontando as vantagens e limitações deste, bem como sugestões para trabalhos futuros. 
REFERENCIAL TEÓRICO

A PROBLEMÁTICA DOS RESÍDUOS SÓLIDOS INDUSTRIAIS NO MEIO AMBIENTE

Segundo Burke et al. (2012) atualmente as cidades geram em média 1,3 bilhões de toneladas de resíduos sólidos por ano, e esse número tende a se aproximar de 2,2 bilhões de toneladas até 2025. Além disso, os custos globais com a destinação e/ou o tratamento desses resíduos, que hoje gira em torno de 205,4 bilhões de dólares por ano, vai chegar a 375,5 bilhões de dólares.

De acordo com Santaella et al. (2014), é possível observar uma relação entre o desenvolvimento industrial e da sociedade de consumo com um aumento na destruição de recursos naturais e alteração no equilíbrio ecológico. Nesse contexto, a má destinação ou tratamento dos resíduos sólidos gerados tem se tornado um problema, e traz consequências ambientais muito graves, como a poluição da água, solo e ar. Além da crescente poluição do meio ambiente, o aumento do uso de matéria prima e consequente diminuição de recursos não renováveis trazem à tona a necessidade de repensar a gestão dos resíduos.

Tendo em vista a crescente necessidade de entender o gerenciamento dos resíduos sólidos e seus impactos na vida das pessoas em escala global, em 2013 o Programa das Nações Unidas para o Meio Ambiente (UNEP) solicita a criação de um documento de avaliação do estado da gestão dos resíduos. O documento que levou o nome de Global Waste Management Outlook (GWMO) tem o intuito de abordar a situação atual na qual o gerenciamento de resíduos se encontra e qual as perspectivas e tendências futuras.

Nesse estudo feito pela UNEP em parceria com a International Waste Management Association, o GWMO, fica claro que a gestão dos resíduos é uma questão complexa e que interfere e se relaciona com os diversos aspectos da sociedade. Dentre eles a mudança climática é um dos aspectos mais abordados nos últimos anos. De acordo com estudo feito pelo Painel Intergovernamental sobre Mudanças Climáticas (IPCC) o gerenciamento de resíduos sólidos contribuiu com 3\% para as emissões de gases de efeito estufa no ano de 2010 (IPCC, 2013). No entanto, Wilson et al. (2015) acredita que ao darmos a atenção devida ao gerenciamento dos resíduos sólidos é possível reduzir entre 15 a $20 \%$ das mudanças climáticas em curto prazo.

Atualmente dados precisos acerca da distribuição dos tipos de resíduos e a quantidade gerada desses são difíceis de ser encontrados. Dessa forma a indisponibilidade de dados configura um dos maiores empecilhos à gestão adequada dos resíduos sólidos no mundo. Nesse contexto, o gráfico gerado pela GWMO (figura 1) se apresenta como uma aproximação das quantidades relativas de resíduos de acordo com sua origem. O gráfico, cujos dados foram obtidos pelas cidades participantes da OECD (Organização para a Cooperação e Desenvolvimento Económico), mostra que os resíduos industriais representam cerca de $21 \%$ de todo o resíduo gerado, sendo uma das maiores fontes de geração de resíduos. 
Figura 1- Porcentagem de resíduo de acordo com sua origem

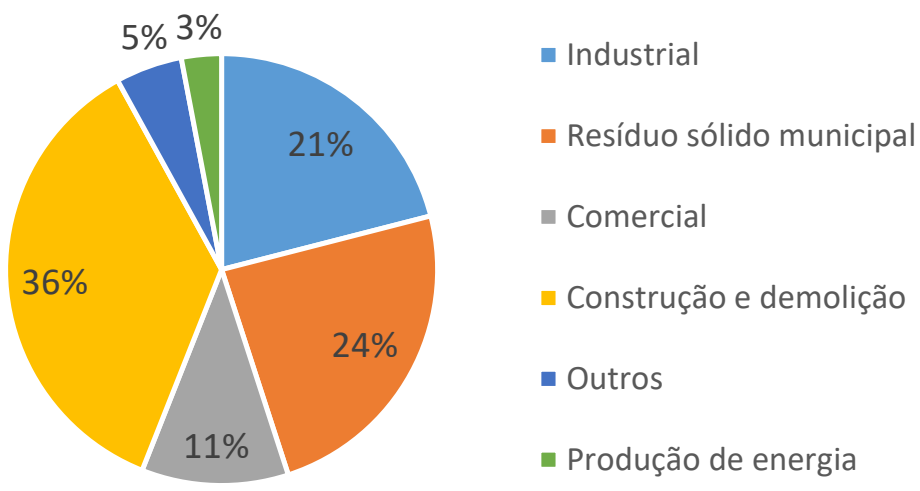

Fonte: Adaptado de Wilson et al., (2015)

No contexto do Brasil, o cenário não é tão diferente da média mundial. A falta de informação acerca das quantidades e tipos de resíduos gerados também se apresenta como um empecilho para a gestão adequada destes. Segundo Ziglio (2014), esse cenário começou a demonstrar sinais de mudança na última década, quando os órgãos governamentais responsáveis passaram a exigir das indústrias estatísticas acerca da sua geração de resíduos.

Em pesquisa feita pela confederação nacional das indústrias - CNI (2010) foi constatado que $62,4 \%$ das indústrias brasileiras possuem procedimentos sistemáticos de gestão ambiental. Das medidas adotadas por essas empresas destacam-se a redução na geração de resíduos em $80,1 \%$ das empresas, sendo esse o programa mais difundido. Além disso, os dados também mostram que os principais fatores que levam as empresas a adotarem um sistema de gerenciamento ambiental são imagem e reputação (78,6\%), exigências do licenciamento ambiental $(77,7 \%)$, regulamentos ambientais $(66,6 \%)$ e política interna das empresas $(65,8 \%)$, o que deixa claro que na maioria dos casos a preocupação com o meio ambiente ainda não parte da cultura das empresas, e sim de uma demanda externa legislativa e de cuidado com a imagem da empresa.

No que diz respeito aos aspectos da legislação ambiental, no ano de 2010 foi instituída no Brasil a lei 12.305 sobre a Política Nacional de Resíduos Sólidos (PNRS). A lei representa um marco ao tratar de questões ambientais de gerenciamento dos resíduos sólidos, pois estabelece diretrizes, metas e ações a serem tomadas, e visa aliar o crescimento econômico ao desenvolvimento sustentável (PAIXÃO, 2012).

\section{A INDÚSTRIA PETROQUÍMICA E A BORRA OLEOSA}

De acordo com Torres (1997) a petroquímica é o ramo da indústria que a partir de matérias primas como petróleo e gás natural produz diversos insumos como plásticos, tintas, solventes, adesivos, gases industriais, entre outros. A indústria petroquímica, segundo Santos (2008) se organiza em 4 gerações, das quais as três primeiras são: extração, refino e insumos básicos (1a geração), resinas termoplásticas (2aㅡ geração) e transformação plástica (3ageração). 
A petroquímica de 1a geração, segundo Santos (2008), é onde são produzidos os insumos básicos como as olefinas que incluem o eteno, propeno e butadieno, e os compostos aromáticos como benzeno, tolueno e xilenos. Já na 2aㅗ geração esses insumos básicos são utilizados para a produção de resinas termoplásticas como o polietileno, PVC, polipropileno, entre outros. Por fim, a petroquímica de 3 a geração é aquela que utiliza as resinas termoplásticas e as transforma em produtos finais.

Segundo Cerqueira (2011) a indústria petroquímica gera em seus processos produtivos uma quantidade considerável de resíduos sólidos. Dentre esses resíduos, um que requer bastante atenção por parte das produtoras e dos órgãos ambientais é a borra oleosa. Por se tratar de um resíduo classificado como classe I pela Associação Brasileira de normas Técnicas - NBR 10004, a borra é considerada um resíduo perigoso e que necessita monitoramento de seu tratamento e/ou disposição.

A composição da borra oleosa é complexa e segundo Cerqueira (2011) depende do processo produtivo da unidade, tipo de separação água e óleo utilizado, dentre outros. No entanto, geralmente essa borra é composta basicamente por água, óleo e sólidos suspensos, e de acordo com Islam (2015), algumas das principais fontes de borra oleosa em plantas petroquímicas são sedimentos de fundo de tanque e resíduo de separador água e óleo. $\mathrm{O}$ autor ainda estima-se que podem ser produzidos mais de 60 milhões de toneladas de borra oleosa por ano. Além disso, é esperado que a geração de borra cresça nos próximos anos devido à alta demanda de produtos vindos do petróleo, o que acende um alerta ainda maior para essa questão.

\section{PRINCIPAIS TRATAMENTOS PARA RESÍDUOS SÓLIDOS}

A maior parte dos resíduos sólidos industriais necessita de tratamento anterior ao seu descarte. Segundo Tocchetto (2005) esses tratamentos se dão geralmente de três formas: conversão do constituinte tóxico do resíduo em um componente não tóxico, destruição desse resíduo tóxico ou separação da fração tóxica reduzindo volume. Existem diversos tipos de tratamento/disposição de resíduos, alguns deles são descritos abaixo:

\section{Gaseificação}

A gaseificação consiste em uma combustão parcial a altas temperaturas com deficiência de oxigênio, e envolve reações entre o carbono e o oxigênio com formação de gás de síntese $\left(\mathrm{CO}_{2}, \mathrm{CO}, \mathrm{CH}_{4}, \mathrm{H}_{2}\right)$. De acordo com Soni e Naik (2016), na gaseificação o resíduo deixa de ser algo inútil, visto que os gases formados podem ser utilizados como combustível para gerar eletricidade ou vapor.

Segundo Soni e Naik (2016) o processo de gaseificação necessita um prétratamento para a retirada de materiais que não podem ser gaseificados, como metais e vidros. Em sequência ao pré-tratamento, de acordo com Arena (2012), o resíduo ainda passa por mais três etapas: aquecimento e secagem, desvolatilização e reações químicas. Já Morris (1998) separa o processo de 
gaseificação em duas etapas, respectivamente: gaseificação e limpeza do gás produto.

É possível observar também que, segundo Soni e Naik (2016), a atmosfera com baixo teor de oxigênio que o processo de gaseificação requer inibe a formação de espécies como SOx e NOx e no lugar dessas produz $\mathrm{H}_{2} \mathrm{~S}, \mathrm{NH}_{3}$ e $\mathrm{N}_{2}$, que são mais fáceis de serem separados do gás de síntese formado. Além disso, de acordo com Marchezetti et al. (2011), no processo de gaseificação há uma redução de até $90 \%$ do volume inicial de resíduo. Por fim, outra vantagem do método é que a atmosfera deficiente em oxigênio inibe a formação de compostos carcinogênicos como dioxinas e furanos.

Por outro lado, Arena (2012) acredita que a metodologia ainda encontra alguma dificuldade para a utilização, devido principalmente à alta heterogeneidade do composto que alimentará o reator e também à falta de plantas de gaseificação ao redor do mundo, que até 2012 girava em torno de 100 unidades.

\section{Incineração}

Segundo Tocchetto (2005), a incineração consiste em uma combustão do material com excesso de oxigênio a temperaturas elevadas. $O$ tratamento visa reduzir o volume do resíduo, tornando-o inerte e gerando energia. De acordo com Marchezetti et al. (2011) a redução de volume de resíduo pode chegar a 99\% do volume inicial.

No processo de incineração o resíduo passa primeiramente por uma etapa de perda de umidade, seguida por uma etapa de volatilização e chegando enfim à etapa de combustão propriamente dita, onde ocorre a oxidação completa do material, de acordo com Machado (2015). Ainda segundo o autor, o processo de incineração geralmente consiste em dois estágios. No primeiro estágio o resíduo é queimado a temperaturas não tão altas e com uma quantidade de oxigênio sub-estequiométrica, gerando gases e parte de resíduos. Já na segunda etapa, a mistura queima a uma temperatura elevada e com excesso de oxigênio para que ocorra a combustão completa.

De acordo com Tocchetto (2005) e Negrão (2010), existe, porém, uma grande preocupação com a possível emanação de compostos altamente tóxicos, como o fosfogênio, dióxido de enxofre, metais pesados, dioxinas, entre outros. Além disso, segundo Negrão (2010) a produção de energia elétrica a partir da incineração tem um aproveitamento de aproximadamente $11 \%$, o que é muito baixo, e pode fazer com que o método não faça mais sentido do ponto de vista de recuperação energética.

\section{Pirólise}

Conforme dito por Muniz (2004) a pirolise consiste em uma decomposição do resíduo através do calor e na ausência ou com o mínimo de oxigênio, de forma a agregar valor ao resíduo. Durante o processo, diferente da incineração, não há combustão do resíduo, e a quase ou total ausência de oxigênio inibe a formação de dioxinas e furanos. Segundo Leme et al. (2017), o processo consiste em três etapas principais: a etapa de secagem, onde os resíduos são aquecidos para a retirada da umidade; a etapa de pirolise, onde são alcançadas temperaturas de até $1600^{\circ} \mathrm{C}$ e onde ocorre a decomposição dos compostos do resíduo, gerando 
uma fração sólida (carbonizada) e uma fração gasosa; e a etapa de condensação dos gases provenientes da etapa anterior, onde são separados os gases não condensáveis da fração líquida.

Segundo Tocchetto (2005), apesar de ser considerada uma tecnologia promissora, ainda existem pontos de limitações. Alguns desses fatores seriam as altas temperaturas necessárias para a quebra dos compostos, o tempo de residência do material no reator, entre outros. Além disso, é preciso atentar também que o processo de pirolise gera, mesmo que pouco, outros resíduos que precisam algumas vezes ser tratados antes do seu descarte.

\section{Co-processamento}

De acordo com Tocchetto (2005) o co-processamento consiste em um processo onde o resíduo é incinerado nos fornos de cimento, servindo como combustível para o processo. As cinzas geradas são incorporadas ao clínquer, matéria prima para produção de cimento. Dessa forma, é possível observar que o método de co-processamento não só reduz a quantidade de resíduo como reutiliza o resíduo gerado durante o processo, evitando a necessidade de destinação.

A indústria de produção de cimento utiliza geralmente combustíveis fósseis, porém a necessidade de manutenção de altas temperaturas exige uma quantidade muito grande de energia, gerando consequentemente um custo alto. Pensando nisso, uma forma de reduzir os custos com combustível é utilizar resíduos que contenham poder calorífico para ser queimados nos fornos, incorporando a cinza gerada na queima ao clínquer.

Por outro lado, mesmo sendo considerada uma alternativa que aparentemente resolve todos os problemas relacionados à destinação do resíduo sólido, o co-processamento em fornos de cimento não é considerado por todos como a melhor alternativa. De acordo com Milanez (2007) durante a queima do resíduo nos fornos parte do poluente é dispersa em forma de emissão atmosférica, o que pode causar problemas ambientais e à saúde das pessoas. Como exemplo, Milanez (2007) cita os metais, que não são destruídos durante o co-processamento, e sim distribuídos no clínquer e nas emissões. Ainda, segundo Rocha et al. (2011), os níveis e característica dessas emissões vão depender do tipo de resíduo utilizado para a queima e dos insumos.

\section{ANALYTIC HIERARCHY PROCESS (AHP)}

\section{Objetivos do Método AHP}

A ideia principal do método de análise hierárquica, mais conhecido pela sua sigla em inglês AHP (Analytic Hierarchy Process), é ser um método de apoio à tomada de decisão em problemas com múltiplos critérios. Ao nos depararmos com um problema, um gesto comum à natureza humana é o de procurar por alternativas para a resolução desse problema. Para fazer a escolha correta geralmente avaliamos essas alternativas baseadas em determinados critérios, que ao serem ponderados nos levam a escolha final. Nesse contexto, o método AHP trabalha com o mesmo raciocínio, porém, ao invés de ficar restrito ao campo 
das ideias ele se estende para o campo da matemática. Desta forma, segundo Frasson (2011), o método se baseia no princípio de que a experiência humana é tão importante quanto os dados disponíveis, e, portanto, é necessária a presença de especialistas no assunto para que a decisão tomada seja a mais adequada para o problema.

\section{Etapas do Método AHP}

Segundo Saaty (2008), para tomar uma decisão de forma organizada é necessário destrinchar a decisão nas seguintes etapas: definição do problema, estruturação da hierarquia da decisão, construção de uma matriz de comparação par a par, atribuição de pesos às prioridades.

- Etapa 1: Definição do problema

Nesta etapa serão escolhidas as alternativas para a resolução do problema. Além disso, serão escolhidos também os critérios que devem ser avaliados em cada uma dessas alternativas. Essas escolhas serão feitas com o auxílio de especialistas da área. Desta forma, será criada uma estrutura hierárquica geral do método, exemplificada na figura 2 .

Figura 2- Estrutura hierárquica geral

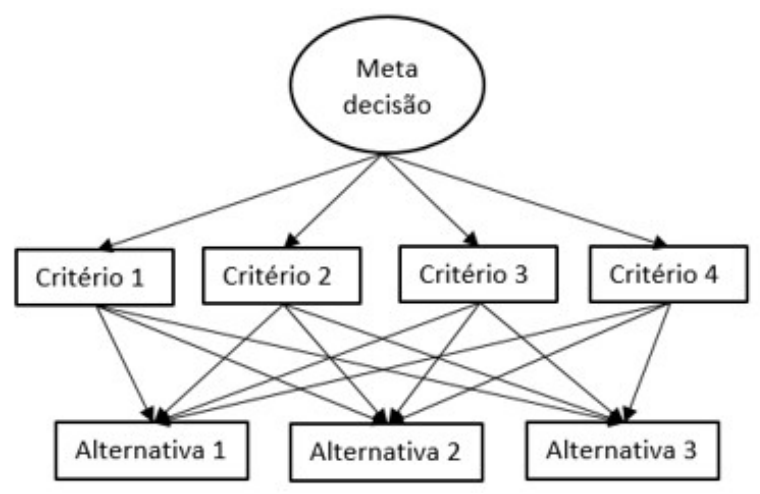

Fonte: Adaptado de Gartner (2001)

- Etapa 2: Aplicação do questionário para coleta de dados e criação da matriz de comparação

Nesta etapa é construído um questionário onde os especialistas deverão atribuir notas para os critérios uns em relação aos outros, de par em par, e para as alternativas em relação a um determinado critério. De acordo com Saaty (2008) para fazer uma comparação é necessário usar uma escala de números que indique o quão mais importante um elemento é sobre o outro. Desta forma, para o presente trabalho será utilizada a escala fundamental de Saaty, mostrada no Quadro 1, que relaciona valores numéricos a valores verbais. O questionário utilizado neste trabalho é mostrado no apêndice. Os resultados obtidos a partir do questionário serão armazenados em uma matriz de comparações paritárias, mostrada na Quadro 2 para os critérios.

Quadro 1- Escala Fundamental de Saaty 


\begin{tabular}{|c|c|c|}
\hline $\begin{array}{l}\text { Intensidade da } \\
\text { importância em escala } \\
\text { absoluta }\end{array}$ & Definição & Explicação \\
\hline 1 & Igual importância & $\begin{array}{l}\text { Os dois elementos contribuem igualmente para o } \\
\text { objetivo }\end{array}$ \\
\hline 3 & $\begin{array}{l}\text { Importância moderada de um } \\
\text { em relação ao outro }\end{array}$ & $\begin{array}{l}\text { Experiência e julgamento favorecem um elemento } \\
\text { sobre o outro }\end{array}$ \\
\hline 5 & $\begin{array}{l}\text { Forte importância de um em } \\
\text { relação ao outro }\end{array}$ & $\begin{array}{l}\text { Experiência e julgamento favorecem fortemente um } \\
\text { elemento sobre o outro }\end{array}$ \\
\hline 7 & $\begin{array}{l}\text { Importância muito forte de um } \\
\text { em relação ao outro }\end{array}$ & $\begin{array}{l}\text { Um elemento é fortemente favorecido em relação } \\
\text { ao outro e sua dominância é demonstrada na } \\
\text { prática }\end{array}$ \\
\hline 9 & $\begin{array}{l}\text { Importância extrema de um } \\
\text { em relação ao outro }\end{array}$ & $\begin{array}{l}\text { A evidencia favorecendo um elemento ao outro é } \\
\text { da maior ordem possivel }\end{array}$ \\
\hline
\end{tabular}

Fonte: Adaptado de Saaty (1990)

Na matriz de comparação paritária o termo $c_{12}$ representa o valor dado pela escala fundamental de Saaty para a importância do critério 1 em relação ao critério 2, ou seja, se o critério 1 for considerado de importância extrema em relação ao critério 2 então no lugar de $c_{12}$ deve-se colocar o número 9 , de acordo com o Quadro 1 e assim por diante.

Quadro 2- Matriz de comparação paritária

\begin{tabular}{|c|c|c|c|c|c|}
\hline Critérios & Crit. 1 & Crit. 2 & Crit. 3 & $\ldots$ & Crit.m \\
\hline Crit. 1 & $c_{11}$ & $c_{12}$ & $c_{13}$ & $\ldots$ & $c_{1 m}$ \\
\hline Crit. 2 & $c_{21}$ & $c_{22}$ & $c_{23}$ & $\ldots$ & $c_{2 m}$ \\
\hline Crit. 3 & $c_{31}$ & $c_{32}$ & $c_{33}$ & $\ldots$ & $c_{3 m}$ \\
\hline$\vdots$ & $\vdots$ & $\vdots$ & $\vdots$ & $\vdots$ & $\vdots$ \\
\hline Crit.m & $c_{m 1}$ & $c_{m 2}$ & $c_{m 3}$ & $\ldots$ & $c_{m m}$ \\
\hline
\end{tabular}

Fonte: Autoria própria (2018)

Segundo Saaty (1990), sabendo que i representa linha e j representa coluna, a matriz de comparação segue as seguintes regras:

1. $c_{i j}=1 / c_{j i}$. Essa regra indica que se na comparação do critério i em relação ao critério j foi dada a importância de valor 5 , então na comparação do critério j em relação ao critério i essa importância terá valor 1/5.

2. $a_{i i}=1$ para todo $i$. Essa regra indica que todo critério, quando comparado a si mesmo, terá a importância de valor 1 , que de acordo com o Quadro 1 significa que tem a mesma importância.

Desta forma, a matriz de comparação terá a seguinte forma: 
Quadro 3 - Matriz de comparação paritária com restrição

\begin{tabular}{|c|c|c|c|c|c|}
\hline Critérios & Crit. 1 & Crit. 2 & Crit. 3 & $\ldots$ & Crit.m \\
\hline Crit. 1 & 1 & $c_{12}$ & $c_{13}$ & $\ldots$ & $c_{1 m}$ \\
\hline Crit. 2 & $1 / c_{12}$ & 1 & $c_{23}$ & $\ldots$ & $c_{2 m}$ \\
\hline Crit. 3 & $1 / c_{13}$ & $1 / c_{23}$ & 1 & $\ldots$ & $c_{3 m}$ \\
\hline$\vdots$ & $\vdots$ & $\vdots$ & $\vdots$ & $\vdots$ & $\vdots$ \\
\hline Crit.m & $1 / c_{1 m}$ & $1 / c_{2 m}$ & $1 / c_{3 m}$ & $\ldots$ & 1 \\
\hline
\end{tabular}

Fonte: Autoria própria (2018)

- Etapa 3: Aplicação do método matemático para a escolha da melhor alternativa.

Etapa 3.1: Encontrar a prioridade média local

Após a confecção da matriz de comparação será utilizada uma técnica matemática chamada autovetor, que calcula os pesos locais e globais dos critérios, de acordo com Frasson (2011). O valor do autovetor é calculado somando-se as colunas.

Em seguida é necessário normalizar os valores da matriz de comparação par a par. Para esse cálculo basta dividir os valores dos julgamentos obtidos no Quadro 2, pela soma da sua respectiva coluna, como ilustrado no Quadro 4.

Quadro 4 - Critérios normalizados

\begin{tabular}{|c|c|c|c|c|c|}
\hline Critérios & Crit. 1 & Crit. 2 & Crit. 3 & $\ldots$ & Crit.m \\
\hline Crit. 1 & $c_{11} / \sum$ Coluna 1 & $c_{12} / \sum$ Coluna 2 & \multicolumn{1}{c|}{$c_{13} / \sum$ Coluna 3} & $\ldots$ & $c_{1 m} / \sum$ Coluna $m$ \\
\hline Crit. 2 & $c_{21} / \sum$ Coluna 1 & $c_{22} / \sum$ Coluna 2 & $c_{23} / \sum$ Coluna 3 & $\ldots$ & $c_{2 m} / \sum$ Coluna $m$ \\
\hline Crit. 3 & $c_{31} / \sum$ Coluna 1 & $c_{32} / \sum$ Coluna 2 & $c_{33} / \sum$ Coluna 3 & $\ldots$ & $c_{3 m} / \sum$ Coluna $m$ \\
\hline$\vdots$ & $\vdots$ & $\vdots$ & $\vdots$ & $\vdots$ & $\vdots$ \\
\hline Crit.m & $c_{m 1} / \sum$ Coluna 1 & $c_{m 2} / \sum$ Coluna 2 & $c_{m 3} / \sum$ Coluna 3 & $\ldots$ & $c_{m m} / \sum$ Coluna $m$ \\
\hline
\end{tabular}

Fonte: Autoria própria (2018)

E por fim, para encontrar a prioridade média local, basta dividir a soma das linhas pela ordem da matriz, como mostra o Quadro 5. 
Quadro 5 - Prioridade média local dos critérios

\begin{tabular}{|c|c|c|c|c|c|c|}
\hline Critérios & Crit. 1 & Crit. 2 & Crit. 3 & $\ldots$ & Crit.m & Prioridade local \\
\hline Crit. 1 & $c_{11 \text { norm }}$ & $c_{12 \text { norm }}$ & $c_{13 \text { norm }}$ & $\ldots$ & $c_{1 \text { mnorm }}$ & $P 1=\sum \operatorname{Linh} a 1 / \mathrm{m}$ \\
\hline Crit. 2 & $c_{21 \text { norm }}$ & $c_{22 \text { norm }}$ & $c_{23 \text { norm }}$ & $\ldots$ & $c_{2 m n o r m}$ & $P 2=\sum \operatorname{Linh} a 2 / \mathrm{m}$ \\
\hline Crit. 3 & $c_{31 \text { norm }}$ & $c_{32 \text { norm }}$ & $c_{33 \text { norm }}$ & $\ldots$ & $c_{3 m n o r m}$ & $P 3=\sum \operatorname{Linh} a 3 / \mathrm{m}$ \\
\hline$\vdots$ & $\vdots$ & $\vdots$ & $\vdots$ & $\vdots$ & $\vdots$ & $\vdots$ \\
\hline Crit.m & $c_{m 1 \text { norm }}$ & $c_{m 2 \text { norm }}$ & $c_{m 3 \text { norm }}$ & $\cdots$ & $c_{\text {mmnorm }}$ & $P 3=\sum$ Linha $\mathrm{m} / \mathrm{m}$ \\
\hline
\end{tabular}

Fonte: Autoria própria (2018)

Etapa 3.2: Analise de consistência lógica (RC)

A inconsistência pode ocorrer devido ao mal julgamento de algum valor de importância de um critério, sendo, portanto, importante analisar a sua possível existência. O valor indicado por Saaty (1987) como limite de inconsistência é de 0,1 . Se esse valor exceder o 0,1 é preciso reestudar o problema e revisar os julgamentos.

De acordo com Martins (2015) a razão de consistência (RC) é dada pelo índice de consistência (IC) dividido pelo índice de consistência randômico (RI).

* Etapa 3.2.1: Cálculo do Índice de consistência (IC)

O índice de consistência é dado por: $I C=\left(\lambda_{\max }-n\right) /(n-1)$, onde $\lambda_{\max }$ é o maior autovalor da matriz de comparação e $\mathrm{n}$ é a dimensão da matriz.

De acordo com Jordão \& Pereira (2006), para encontrar o $\lambda_{\max }$ são necessárias duas etapas:

- Etapa 3.2.1.1: Determinação da totalização das entradas

Nesse passo é feita a multiplicação do valor do julgamento da matriz de comparação inicial dos critérios pelo vetor da prioridade local, mostrado no Quadro 6:

Quadro 6 - Determinação de totalização das entradas

\begin{tabular}{|c|c|c|c|c|c|}
\hline Critérios & Crit. 1 & Crit. 2 & Crit. 3 & $\ldots$ & Crit.m \\
\hline Crit. 1 & $c_{11}$ & $c_{12}$ & $c_{13}$ & $\ldots$ & $c_{1 m}$ \\
\hline Crit. 2 & $c_{21}$ & $c_{22}$ & $c_{23}$ & $\ldots$ & $c_{2 m}$ \\
\hline Crit. 3 & $c_{31}$ & $c_{32}$ & $c_{33}$ & $\ldots$ & $c_{3 m}$ \\
\hline$\vdots$ & $\vdots$ & $\vdots$ & $\vdots$ & $\vdots$ & $\vdots$ \\
\hline Crit.m & $c_{m 1}$ & $c_{m 2}$ & $c_{m 3}$ & $\ldots$ & $c_{m m}$ \\
\hline
\end{tabular}

\begin{tabular}{|c|}
\hline $\begin{array}{c}\text { Prioridade média } \\
\text { local }\end{array}$ \\
\hline $\mathrm{P} 1$ \\
\hline $\mathrm{P} 2$ \\
\hline $\mathrm{P} 3$ \\
\hline$\vdots$ \\
\hline $\mathrm{Pm}$ \\
\hline
\end{tabular}

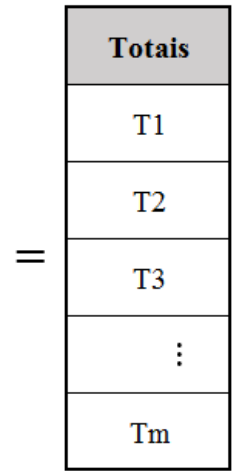

Fonte: Jordão \& Pereira (2006) 
- Etapa 3.2.1.2 Vetor auxiliar na determinação de $\lambda_{\max }$

Nesta etapa os valores totais obtidos no passo anterior são divididos pelas suas respectivas prioridades locais. Em seguida é calculado o $\lambda_{\max }$, dado pela soma dos valores obtidos anteriormente dividido pela ordem do vetor prioridade (Figura 3)

Figura 3 - Calculo de vetor auxiliar

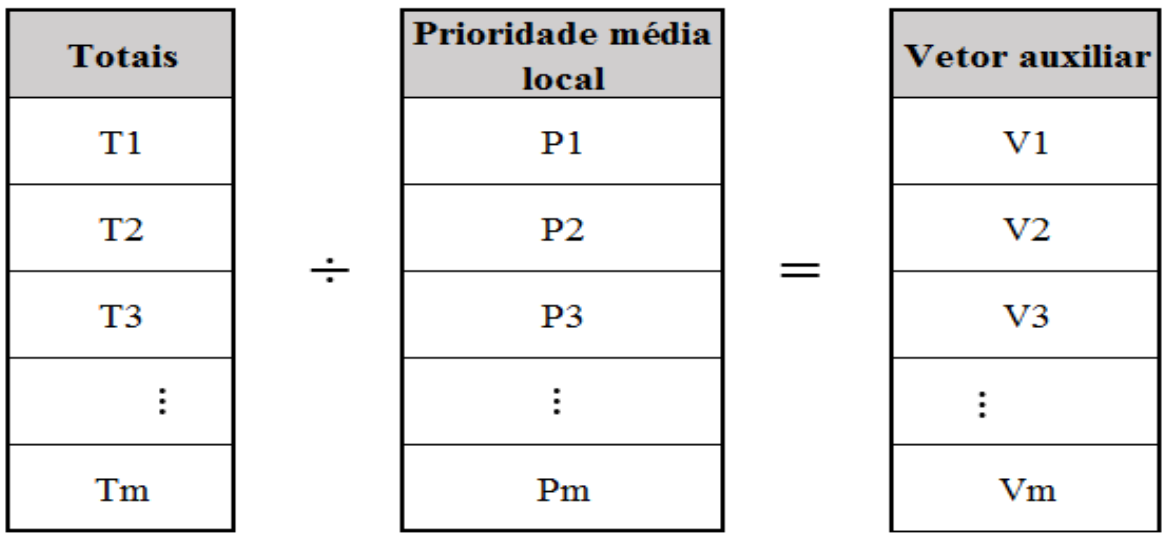

Fonte: Adaptado de Jordão \& Pereira (2006)

$$
\lambda_{\max }=\frac{V 1+V 2+V 3+\cdots+V m}{m}
$$

Etapa 3.2.2: Cálculo do índice de consistência randômico (RI)

Saaty (1987) propõe um quadro com valores de índice de consistência randômico de acordo com a dimensão da matriz de comparação, cada um desses numeros é um índice médio de consistência aleatória (RI) derivado de uma amostra de tamanho 500, de uma matriz recíproca gerada aleatoriamente. 0 Quadro 7 é mostrado abaixo, onde $n$ é a ordem da matriz:

Quadro 7 - Índice de consistência aleatório

\begin{tabular}{|l|cccccccccc|}
\hline $\mathbf{n}$ & 1 & 2 & 3 & 4 & 5 & 6 & 7 & 8 & 9 & 10 \\
\hline $\mathbf{R I}$ & 0 & 0 & 0,58 & 0,9 & 1,12 & 1,24 & 1,32 & 1,41 & 1,45 & 1,49 \\
\hline
\end{tabular}

Fonte: Saaty (1987)

- Etapa 3.3: avaliar alternativas por critério

Após fazer a análise dos critérios par a par, é preciso avaliar as alternativas entre si com relação a cada critério. Desta forma, se seguirmos o ilustrado pela Figura 2 devemos ter quatro matrizes (uma para cada critério) de ordem $3 \times 3$ cada. Os cálculos realizados seguem os mesmos passos usados anteriormente para a matriz par a par dos critérios, onde encontramos o vetor decisão, o $\lambda_{\max }$ e o IC.

Sendo assim, teremos uma matriz para cada critério das alternativas par a par seguindo o modelo do Quadro 8. 
Quadro 8 - Matriz de comparação paritária por critério

\begin{tabular}{|c|c|c|c|c|c|c|c|c|c|}
\hline Critério 1 & $\begin{array}{c}\text { Alternativa } \\
1 \\
\end{array}$ & $\begin{array}{c}\text { Alternativa } \\
2 \\
\end{array}$ & $\begin{array}{c}\text { Alternativa } \\
\mathbf{3} \\
\end{array}$ & $\begin{array}{l}\text { Prioridade } \\
\text { média local }\end{array}$ & Critério 2 & $\begin{array}{c}\text { Alternativa } \\
1\end{array}$ & $\begin{array}{c}\text { Alternativa } \\
2 \\
\end{array}$ & $\begin{array}{c}\text { Alternativa } \\
3 \\
\end{array}$ & $\begin{array}{l}\text { Prioridade } \\
\text { média local }\end{array}$ \\
\hline Alternativa 1 & $w_{11}$ & $w_{12}$ & $w_{13}$ & $\mathrm{w}_{1}$ & Alternativa 1 & $x_{11}$ & $x_{12}$ & $x_{13}$ & $\mathrm{X}_{1}$ \\
\hline Alternativa 2 & $w_{21}$ & $w_{22}$ & $w_{23}$ & $\mathrm{~W}_{2}$ & Alternativa 2 & $x_{21}$ & $x_{22}$ & $x_{23}$ & $\mathrm{X}_{2}$ \\
\hline Alternativa 3 & $w_{31}$ & $w_{32}$ & $w_{33}$ & $\mathrm{~W}_{3}$ & Alternativa 3 & $x_{31}$ & $x_{32}$ & $x_{33}$ & $\mathrm{X}_{3}$ \\
\hline & \multicolumn{4}{|c|}{$\lambda_{\text {máx }}, I C$} & & \multicolumn{4}{|c|}{$\lambda_{\text {máx }}, I C$} \\
\hline Critério 3 & $\begin{array}{c}\text { Alternativa } \\
\quad 1\end{array}$ & $\begin{array}{c}\text { Alternativa } \\
2\end{array}$ & $\begin{array}{c}\text { Alternativa } \\
3\end{array}$ & $\begin{array}{c}\text { Prioridade } \\
\text { média local }\end{array}$ & Critério 4 & $\begin{array}{c}\text { Alternativa } \\
1\end{array}$ & $\begin{array}{c}\text { Alternativa } \\
2\end{array}$ & $\begin{array}{c}\text { Alternativa } \\
3\end{array}$ & $\begin{array}{l}\text { Prioridade } \\
\text { média local }\end{array}$ \\
\hline Alternativa 1 & $y_{11}$ & $y_{12}$ & $y_{13}$ & $\mathrm{Y}_{1}$ & Alternativa 1 & $z_{11}$ & $z_{12}$ & $z_{13}$ & $Z_{1}$ \\
\hline Alternativa 2 & $y_{21}$ & $y_{22}$ & $y_{23}$ & $\mathrm{Y}_{2}$ & Alternativa 2 & $z_{21}$ & $z_{22}$ & $z_{23}$ & $\mathrm{Z}_{2}$ \\
\hline Alternativa 3 & $y_{31}$ & $y_{32}$ & $y_{33}$ & $\mathrm{Y}_{3}$ & Alternativa 3 & $z_{31}$ & $z_{32}$ & $z_{33}$ & $Z_{3}$ \\
\hline
\end{tabular}

Fonte: adaptado de Saaty (1990).

- Etapa 3.4: Construção da matriz decisão e resultado final

O último passo do método AHP consiste na criação da matriz de decisão, onde todas as prioridades locais serão dispostas como mostra o Quadro 9. Para o cálculo do vetor prioridade global das alternativas é preciso multiplicar o vetor linha de cada alternativa pelo vetor prioridade dos critérios, assim como mostrado no Quadro 9. Desta forma, a alternativa que obtiver maior valor é a que deve ser escolhida.

Quadro 9 - Matriz de decisão

\begin{tabular}{|c|cccc|c|}
\hline $\begin{array}{c}\text { Critérios/ } \\
\text { Alternativas }\end{array}$ & Critério 1 & Critério 2 & Critério 3 & Critério 4 & \multirow{2}{*}{ Vetor decisão } \\
\cline { 2 - 5 } Vetor critérios & $\mathrm{P} 1$ & $\mathrm{P} 2$ & $\mathrm{P} 3$ & $\mathrm{P} 4$ & \\
\hline Alternativa 1 & $\mathrm{W} 1$ & $\mathrm{X} 1$ & $\mathrm{Y} 1$ & $\mathrm{Z} 1$ & $=(W 1 \times P 1)+(X 1 \times P 2)+(Y 1+P 3)+(Z 1+P 4)$ \\
Alternativa 2 & $\mathrm{W} 2$ & $\mathrm{X} 2$ & $\mathrm{Y} 2$ & $\mathrm{Z} 2$ & $=(W 2 \times P 1)+(X 2 \times P 2)+(Y 2+P 3)+(Z 2+P 4)$ \\
Alternativa 3 & $\mathrm{W} 3$ & $\mathrm{X} 3$ & $\mathrm{Y} 3$ & $\mathrm{Z} 3$ & $=(W 3 \times P 1)+(X 3 \times P 2)+(Y 3+P 3)+(Z 3+P 4)$ \\
\hline
\end{tabular}

Fonte: Autoria própria (2018)

\section{O método AHP e sua Aplicação em Resíduos Sólidos}

De acordo com Goulart et al. (2017) o crescimento populacional, a urbanização e o desenvolvimento econômico tem levado a uma preocupação crescente com relação ao gerenciamento dos resíduos sólidos. Por ter se tornado um tema demasiadamente discutido, as decisões que levam em conta fatores ambientais, segundo Huang et al. (2011) são geralmente complexas e exigem uma análise multidisciplinar. Dessa forma, se faz necessário o uso de uma estrutura sistemática que nos permita organizar e analisar os dados de forma mais assertiva para a tomada de uma decisão (HUANG et al., 2011).

Nesse contexto surge a análise de decisão multi-critério (MCDM ou MCDA), que segundo Huang et al. (2011) é uma metodologia que através da combinação 
dos dados com informações de custo/benefício e visões das partes interessadas visa classificar as alternativas disponíveis. Dentro das análises de multi-critério existem diversos métodos diferentes, cada um com suas vantagens e desvantagens.

O estudo feito por Goulart et al. (2017) utiliza 260 artigos relacionados ao uso de métodos MCDM no gerenciamento de resíduos sólidos, que foram obtidos através de diversas bases de pesquisa como Science Direct, Scopus, Wiley Online Library, entre outros. Para analisar todos os artigos foi necessário identificar palavras chave que consideravam determinados aspectos como: tipo de métodos MCDM, tipo de resíduo, objetivo do trabalho, entre outros. Além disso, para evitar erros no processo de análise dos dados, a divisão dos artigos de acordo com as palavras chave foi feita por dois pesquisadores de forma separada, e posteriormente em casos de divergências esses pontos eram discutidos. (GOULART et al., 2017)

Outro estudo analisado neste trabalho foi o de Huang et al. (2011). O estudo teve o objetivo de fazer uma revisão bibliográfica dos artigos publicados que utilizaram métodos MCDA aplicado à área de meio ambiente. A grande maioria dos artigos selecionados foram retirados da base de dados da Web of Science (WOS), além do Journal of Multi-criteria decision analysis e Integrated Environmental Assessment and Management. A pesquisa foi feita associando a palavra-chave "MCDA" e refinada pelo assunto "meio ambiente", do ano de 1990 até 2010 e contou com um total de 312 artigos. Os artigos que datam de 1990 a 2000 foram utilizados somente para a análise de tendência histórica, enquanto que os artigos que datam de 2000 a 2010 foram classificados para posteriores análises. As classificações feitas por Huang et al. (2011) se resumem a três categorias: método MCDA utilizado, área de aplicação e ferramentas complementares.

Em um terceiro estudo feito por Achillas et al. (2013) é feita uma revisão bibliográfica de artigos publicados que aplicam métodos MCDA na resolução de problemas de gerenciamento de resíduos. As publicações são classificadas de acordo com o método MCDA, ano de publicação e tipo de resíduo (ACHILLAS et al., 2013). Além disso, diferente dos dois outros estudos mencionados, Achillas et al. (2013) faz ainda um outro agrupamento das publicações, separando-as em publicações que falam sobre os tipos de tratamento e disposição final do resíduo

Na publicação de Goulart et al. (2017) foi constatado que em 35\% dos artigos analisados o método AHP foi utilizado, representando a maioria dos casos. Já no estudo feito por Huang et al. (2011) do total de publicações analisadas $48 \%$ utilizaram o método $\mathrm{AHP}$, enquanto que na revisão bibliográfica feita por Achillas et al. (2013) 34\% dos artigos analisados aproximadamente utilizava o método AHP, sendo este, portanto o método mais utilizado.

A partir dos estudos analisados podemos perceber que o método AHP tem sido muito utilizado quando o assunto é resíduo sólido. Um exemplo de estudos publicados é o de Marchezetti et al. (2011). Os autores aplicaram o método AHP para a determinação da destinação mais adequada para os resíduos sólidos domiciliares gerados pelos municípios que fazem parte da região metropolitana de Curitiba. Nesse trabalho foram selecionados 11 critérios e 7 alternativas de destinação, e como resultado da aplicação do método foi definido que a reciclagem era a melhor alternativa neste caso. A autora salienta também que para cada cenário diferente será necessário comparar as tecnologias em função 
da nova condição adotada e, portanto, cada resultado é único, mesmo que leve em consideração as mesmas alternativas.

Já em outro estudo feito por Frasson (2011), o método AHP é utilizado como suporte para a tomada de decisão acerca da melhor alternativa para o tratamento e destinação de lodo biológico de agroindústrias. O trabalho foi aplicado em duas agroindústrias, uma de café solúvel e outra de processamento e embalagem de grão e cereais. A escolha das alternativas e critérios contou com a colaboração de especialistas de ambas as empresas e foram determinadas três alternativas e seis critérios. Para a primeira indústria e o resultado obtido como melhor alternativa foi a incineração com recuperação de energia, com $49 \%$ de preferência. Já para o segundo caso a alternativa considerada como mais adequada foi a disposição em solo agrícola, com $39 \%$ de preferência. Como conclusão do trabalho, o autor atesta que o método se mostrou simples e de fácil uso, permitindo que o objetivo do trabalho fosse alcançado.

Segundo Goulart et al. (2017), a predominância do método AHP em detrimento dos outros métodos existentes é devido à sua adequação aos tipos de problemas de gerenciamento de resíduos sólidos, pois o método permite que a parte interessada atribua pesos aos critérios e alternativas, o que no contexto do gerenciamento de resíduos é de frequente necessidade. Além disso, segundo Huang et al. (2011), a ampla utilização do método AHP nos temas relacionados ao meio ambiente, principalmente no gerenciamento de resíduos sólidos, pode estar relacionado com a disponibilidade de softwares que possibilitam o uso do método de forma fácil.

As revisões feitas por Goulart et al. (2017) e Huang et al. (2011) mostram um crescimento considerável de publicações que utilizam métodos de MCDM na área ambiental nos últimos anos. Huang et al. (2011) acreditam que esse crescimento pode ser devido ao aumento da complexidade dos problemas, bem como da disponibilidade de informações e da necessidade de uma tomada de decisão mais bem embasada. Dessa forma, é possível esperar um aumento promissor no uso dos métodos MCDM na área ambiental.

\section{MÉTODO}

\section{CARACTERIZAÇÃO DA PESQUISA}

O trabalho em questão tem o intuito de mostrar de forma prática como o método AHP pode ser uma ferramenta importante para tomada de decisão até mesmo em locais complexos como a indústria petroquímica. A partir dos resultados obtidos pelos questionários elaborados, e baseado nos critérios escolhidos, será possível chegar a um resultado que nos dará a informação de qual a melhor alternativa para tratamento de um resíduo muito comum da indústria petroquímica, a borra oleosa.

O trabalho consistiu basicamente em três pontos principais. A primeira etapa consistiu em um estudo acerca do tema "resíduos sólidos" e mais especificamente os tratamentos e destinações existentes atualmente para a borra oleosa. A segunda etapa do trabalho consistiu em estudar o método AHP. Por fim, a última etapa consistiu na aplicação do método AHP, a partir dos 
resultados obtidos pelos questionários para o resíduo em questão e análise dos resultados.

O resíduo abordado no trabalho é proveniente de uma indústria petroquímica localizada no polo petroquímico de Camaçari. A primeira e segunda etapa do método AHP, que consistem na escolha das alternativas e critérios e na aplicação do questionário, foram realizadas com o auxílio de especialistas da área da empresa em questão. Dessa forma, foram realizadas duas reuniões com a equipe. Na primeira reunião foi realizado um brainstorming para a escolha das alternativas e critérios. Já na segunda reunião os especialistas responderam os questionários de forma que as escolhas das notas (considerando a escala numérica de Saaty) foram dadas em conjunto.

Por fim, com os resultados obtidos através dos questionários foi possível a implementação do método AHP para a escolha da melhor alternativa de tratamento para o resíduo.

\section{COLETA DE DADOS}

Os dados foram obtidos através de questionários elaborados pela autora. Para o preenchimento desses questionários foi requisitado que três engenheiros químicos que trabalham na área de meio ambiente da empresa utilizada no estudo de caso da pesquisa participassem. Os especialistas têm conhecimento no assunto e conhecem bem todas as alternativas apresentadas no trabalho.

O questionário consiste em uma série de quadros onde os especialistas devem indicar, par a par, quais critérios eles consideram mais importantes, quais alternativas em relação a determinado critério eles acreditam ser mais importantes e qual o nível dessas importâncias. Os questionários podem ser vistos no apêndice.

\section{APLICAÇÃO DO MÉTODO AHP NA EMPRESA ALVO DE ESTUDO}

Para a aplicação do método foi necessário passar os dados obtidos pelos questionários para as matrizes de comparação paritária. Em seguida, todos os passos do método AHP descritos no capitulo 2.4 do presente trabalho foram seguidos.

\section{Critérios e Alternativas para Tomada de Decisão pelos Especialistas da Empresa Estudada}

Para a determinação dos critérios e alternativas foram estudados cinco critérios e quatro alternativas. Quanto aos critérios foram escolhidos:

1. Poluentes gerados (Resíduos, efluente, emissão atmosférica): Refere-se à quantidade de poluentes que determinada alternativa gera. Quanto menos poluentes são gerados, mais ambientalmente adequado é o método;

2. Custo de investimento na tecnologia: Refere-se ao custo esperado caso não exista empresa terceira que realize o determinado tratamento ou disposição e seja necessário implementar nova tecnologia na própria planta;

3. Custo com o tratamento: Refere-se aos custos com o tratamento ou destinação do resíduo para aquela alternativa; 
4. Fator logístico: Refere-se ao transporte do resíduo até o local de tratamento/destinação;

5. Aproveitamento energético: Refere-se à possibilidade de a tecnologia de tratamento reverter parte do resíduo em energia.

As alternativas escolhidas para o tratamento/destinação da borra oleosa foram abordadas na seção 2.3 , sendo elas:
1. Gaseificação
2. Incineração
3. Pirolise
4. Co-processamento

\section{Aplicação do Método}

A aplicação do método seguiu o passo a passo demonstrado no item 2.4. Foi realizado estudo acerca das alternativas e critérios considerados adequados para a resolução do problema a serem utilizados e após esse estudo foi possível a criação da estrutura hierárquica. A estrutura hierárquica geral do método é demonstrada na Figura 4. Os critérios e alternativas foram explicados no item 3.3.1.

Figura 4 - Hierarquização do problema

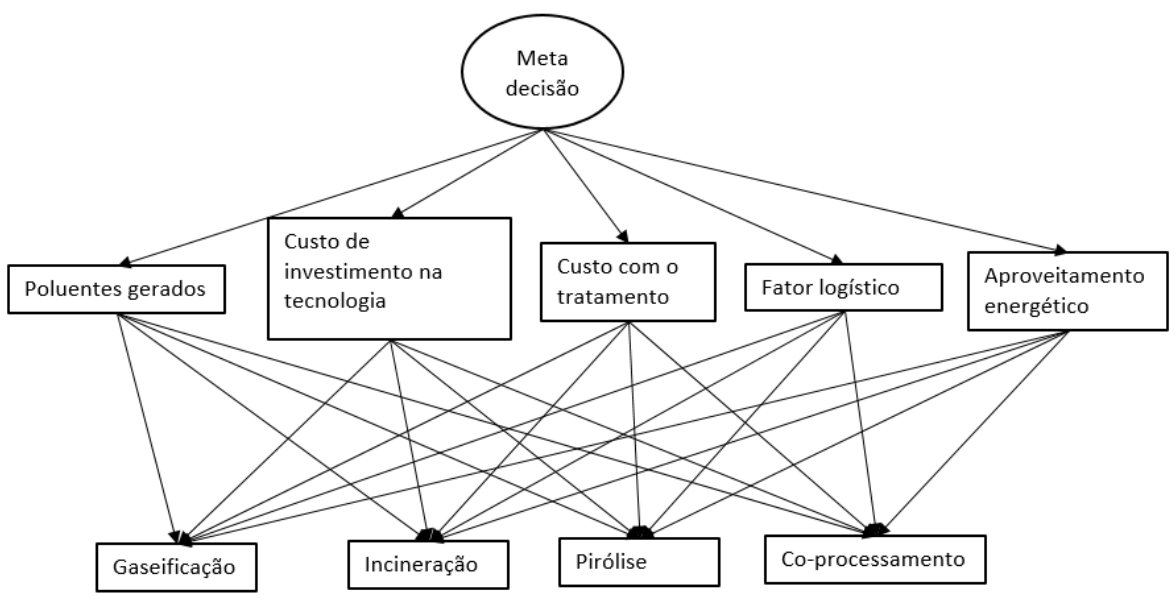

Fonte: Adaptado de Gartner (2001)

\section{RESULTADOS E DISCUSSÕES}

Através da metodologia AHP foi possível chegar a um resultado de tratamento mais indicado para o resíduo em questão. $O$ preenchimento do questionário foi feito por uma equipe de três especialistas da área de meio ambiente que trabalham na empresa. Durante as reuniões a equipe discutiu como chegar a uma conclusão nas respostas, o que leva a uma maior confiabilidade nas respostas e menores chances de inconsistência nas mesmas, confirmado nos Quadros de resultado mostrados abaixo. 
Os resultados obtidos para a comparação entre os critérios podem ser observados no Quadro 10.

Quadro 10 - Resultado das matrizes de comparação paritária dos critérios

\begin{tabular}{|l|c|c|c|c|c|}
\hline Critérios & Critério 1 & Critério 2 & Critério 3 & Critério 4 & Critério 5 \\
\hline Critério 1 & 1 & 5 & 3 & 7 & 5 \\
\hline Critério 2 & $1 / 5$ & 1 & 1 & 3 & 5 \\
\hline Critério 3 & $1 / 3$ & 1 & 1 & 5 & 5 \\
\hline Critério 4 & $1 / 7$ & $1 / 3$ & $1 / 5$ & 1 & 3 \\
\hline Critério 5 & $1 / 5$ & $1 / 5$ & $1 / 5$ & $1 / 3$ & 1 \\
\hline
\end{tabular}

Fonte: Autoria própria (2018)

Legenda:

Critério 1 - Poluentes gerados.

Critério 2 -- Custo de investimento na tecnologia.

Critério 3 - Custo com o tratamento.

Critério 4 - Fator logístico.

Critério 5 - Aproveitamento energético.

Em seguida foi feita a normalização das notas e foi calculado o vetor prioridade média local, cujos resultados podem ser observados no Quadro 11:

Quadro 11 - Normalização dos valores dos critérios e cálculo da prioridade média local

\begin{tabular}{|c|c|c|c|c|c|c|}
\hline Critérios & Critério 1 & Critério 2 & Critério 3 & Critério 4 & Critério 5 & $\begin{array}{c}\text { Prioridade média } \\
\text { local }\end{array}$ \\
\hline Critério 1 & 0,533 & 0,664 & 0,556 & 0,429 & 0,263 & 0,489 \\
\hline Critério 2 & 0,107 & 0,133 & 0,185 & 0,184 & 0,263 & 0,174 \\
\hline Critério 3 & 0,178 & 0,133 & 0,185 & 0,306 & 0,263 & 0,213 \\
\hline Critério 4 & 0,076 & 0,044 & 0,037 & 0,061 & 0,158 & 0,075 \\
\hline Critério 5 & 0,107 & 0,027 & 0,037 & 0,020 & 0,053 & 0,049 \\
\hline \multicolumn{7}{|c|}{$\lambda_{\text {máx }}=5,391, I C=0,098, R C=0,087$} \\
\hline
\end{tabular}

Fonte: Autoria própria (2018)

Legenda:

Critério 1 - Poluentes gerados.

Critério 2 -- Custo de investimento na tecnologia.

Critério 3 - Custo com o tratamento.

Critério 4 - Fator logístico

Critério 5 - Aproveitamento energético. 
A prioridade média local mostra qual critério foi considerado como mais importante para os tomadores de decisão e qual a grandeza dessa importância.

É possível observar no Quadro 11 que todos os valores de índice de consistência se encontram abaixo de 0,1, como recomendado por Saaty (1987), o que significa que as escolhas possuem consistência satisfatória.

A partir dos resultados acima, foi possível observar que dentre os critérios apresentados, o primeiro (Poluentes gerados $-0,489$ ) se mostrou como o mais importante para os especialistas. Nesse critério foi observada a geração de efluente liquido, resíduo sólido e emissão atmosférica. Essa importância dada ao critério de poluentes gerados por parte dos especialistas mostra uma crescente preocupação com os possíveis impactos ambientais causados pela ação humana.

Já o critério de aproveitamento energético foi considerado como menos importante $(0,049)$. Isto porque, o principal intuito desse trabalho é escolher um método termoquímico para tratar o resíduo em questão, focando na mitigação do seu impacto ambiental e não na geração de energia.

Em seguida, a partir das respostas obtidas através do segundo questionário, foi possível obter as seguintes matrizes de comparação para as alternativas (Quadro 12):

Quadro 12 - Resultado das matrizes de comparação paritária das alternativas

\begin{tabular}{|c|c|c|c|c|c|c|c|c|c|}
\hline Critério 1 & $\begin{array}{c}\text { Alternativa } \\
\quad 1\end{array}$ & $\begin{array}{c}\text { Alternativa } \\
2\end{array}$ & $\begin{array}{c}\text { Alternativa } \\
3 \\
\end{array}$ & $\begin{array}{c}\text { Alternativa } \\
4\end{array}$ & Critério 2 & $\begin{array}{c}\text { Alternativa } \\
\quad 1\end{array}$ & $\begin{array}{c}\text { Alternativa } \\
2\end{array}$ & $\begin{array}{c}\text { Alternativa } \\
3\end{array}$ & $\begin{array}{c}\text { Alternativa } \\
4\end{array}$ \\
\hline Alternativa 1 & 1 & 7 & $1 / 3$ & 5 & Alternativa 1 & 1 & 3 & $1 / 3$ & 5 \\
\hline Alternativa 2 & $1 / 7$ & 1 & $1 / 9$ & $1 / 3$ & Alternativa 2 & $1 / 3$ & 1 & $1 / 5$ & 1 \\
\hline Alternativa 3 & 3 & 9 & 1 & 5 & Alternativa 3 & 3 & 5 & 1 & 7 \\
\hline Alternativa 4 & $1 / 5$ & 3 & $1 / 5$ & 1 & Alternativa 4 & $1 / 5$ & 1 & $1 / 7$ & 1 \\
\hline Critério 3 & $\begin{array}{c}\text { Alternativa } \\
1\end{array}$ & $\begin{array}{l}\text { Alternativa } \\
2\end{array}$ & $\begin{array}{c}\text { Alternativa } \\
\mathbf{3}\end{array}$ & $\begin{array}{c}\text { Alternativa } \\
4\end{array}$ & Critério 4 & $\begin{array}{c}\text { Alternativa } \\
1\end{array}$ & $\begin{array}{c}\text { Alternativa } \\
\mathbf{2}\end{array}$ & $\begin{array}{c}\text { Alternativa } \\
3\end{array}$ & $\begin{array}{c}\text { Alternativa } \\
4\end{array}$ \\
\hline Alternativa 1 & 1 & $1 / 3$ & 1 & $1 / 5$ & Alternativa 1 & 1 & $1 / 5$ & 1 & $1 / 5$ \\
\hline Alternativa 2 & 3 & 1 & 3 & $1 / 3$ & Alternativa 2 & 5 & 1 & 5 & 1 \\
\hline Alternativa 3 & 1 & $1 / 3$ & 1 & $1 / 5$ & Alternativa 3 & 1 & $1 / 5$ & 1 & $1 / 5$ \\
\hline \multirow[t]{6}{*}{ Alternativa 4} & 5 & 3 & 5 & 1 & Alternativa 4 & 5 & 1 & 5 & 1 \\
\hline & & & Critério 5 & $\begin{array}{c}\text { Alternativa } \\
\quad 1 \\
\end{array}$ & $\begin{array}{c}\text { Alternativa } \\
\mathbf{2} \\
\end{array}$ & $\begin{array}{c}\text { Alternativa } \\
\mathbf{3} \\
\end{array}$ & $\begin{array}{c}\text { Alternativa } \\
4 \\
\end{array}$ & & \\
\hline & & & Alternativa 1 & 1 & 7 & 3 & 5 & & \\
\hline & & & Alternativa 2 & $1 / 7$ & 1 & $1 / 5$ & $1 / 3$ & & \\
\hline & & & Alternativa 3 & $1 / 3$ & 5 & 1 & 5 & & \\
\hline & & & Alternativa 4 & $1 / 5$ & 3 & $1 / 5$ & 1 & & \\
\hline
\end{tabular}

Fonte: Autoria própria (2018)

Legenda:

Alternativa 1 - Gaseificação.

Alternativa 2 - Incineração.

Alternativa 3 - Pirólise.

Alternativa 4 - Co-processamento 
Os valores das matrizes foram normalizados e o vetor prioridade média local foi calculado, obtendo como resultado os valores apontados no Quadro 13.

Quadro 13 - Normalização dos valores das alternativas e cálculo da prioridade média local

\begin{tabular}{|c|c|c|c|c|c|c|c|c|c|c|c|}
\hline Critério 1 & $\begin{array}{c}\text { Alternativa } \\
1\end{array}$ & $\begin{array}{c}\text { Alternativa } \\
2\end{array}$ & $\begin{array}{c}\text { Alternativa } \\
3\end{array}$ & $\begin{array}{c}\text { Alternativa } \\
4\end{array}$ & $\begin{array}{c}\text { Prioridade } \\
\text { média Local }\end{array}$ & Critério 2 & $\begin{array}{c}\text { Alternativa } \\
1\end{array}$ & $\begin{array}{c}\text { Alternativa } \\
\mathbf{2}\end{array}$ & $\begin{array}{c}\text { Alternativa } \\
3\end{array}$ & $\begin{array}{c}\text { Alternativa } \\
4\end{array}$ & $\begin{array}{l}\text { Prioridade } \\
\text { média Local }\end{array}$ \\
\hline Alternativa 1 & 0,230 & 0,350 & 0,203 & 0,441 & 0,306 & Alternativa 1 & 0,221 & 0,300 & 0,199 & 0,357 & 0,269 \\
\hline Alternativa 2 & 0,033 & 0,050 & 0,068 & 0,029 & 0,045 & Alternativa 2 & 0,074 & 0,100 & 0,119 & 0,071 & 0,091 \\
\hline Alternativa 3 & 0,691 & 0,450 & 0,608 & 0,441 & 0,548 & Alternativa 3 & 0,662 & 0,500 & 0,597 & 0,500 & 0,565 \\
\hline Alternativa 4 & 0,046 & 0,150 & 0,122 & 0,088 & 0,101 & Alternativa 4 & 0,044 & 0,100 & 0,085 & 0,071 & 0,075 \\
\hline \multicolumn{6}{|c|}{$\lambda_{\text {máx }}=4,179, I C=0,060, R C=0,066$} & \multicolumn{6}{|c|}{$\lambda_{\text {máx }}=4,083, I C=0,028, R C=0,031$} \\
\hline Critério 3 & $\begin{array}{c}\text { Alternativa } \\
1\end{array}$ & $\begin{array}{c}\text { Alternativa } \\
\quad 2\end{array}$ & $\begin{array}{c}\text { Alternativa } \\
3\end{array}$ & $\begin{array}{c}\text { Alternativa } \\
4\end{array}$ & $\begin{array}{c}\text { Prioridade } \\
\text { média Local }\end{array}$ & Critério 4 & $\begin{array}{c}\text { Alternativa } \\
1\end{array}$ & $\begin{array}{c}\text { Alternativa } \\
2\end{array}$ & $\begin{array}{c}\text { Alternativa } \\
3\end{array}$ & $\begin{array}{c}\text { Alternativa } \\
4\end{array}$ & $\begin{array}{l}\text { Prioridade } \\
\text { média Local }\end{array}$ \\
\hline Alternativa 1 & 0,100 & 0,071 & 0,100 & 0,115 & 0,097 & Alternativa l & 0,125 & 0,125 & 0,125 & 0,125 & 0,125 \\
\hline Alternativa 2 & 0,300 & 0,214 & 0,300 & 0,192 & 0,252 & Alternativa 2 & 0,375 & 0,375 & 0,375 & 0,375 & 0,375 \\
\hline Alternativa 3 & 0,100 & 0,071 & 0,100 & 0,115 & 0,097 & Alternativa 3 & 0,125 & 0,125 & 0,125 & 0,125 & 0,125 \\
\hline Alternativa 4 & 0,500 & 0,643 & 0,500 & 0,577 & 0,555 & Alternativa 4 & 0,375 & 0,375 & 0,375 & 0,375 & 0,375 \\
\hline \multicolumn{6}{|c|}{$\lambda_{\text {máx }}=4,044 I C=0,0145, R C=0,0161$} & \multicolumn{6}{|c|}{$\lambda_{\max x}=4,000, I C=0, R C=0$} \\
\hline & & & Critério 5 & $\begin{array}{c}\text { Alternativa } \\
1 \\
\end{array}$ & $\begin{array}{c}\text { Alternativa } \\
\mathbf{2} \\
\end{array}$ & $\begin{array}{c}\text { Alternativa } \\
\mathbf{3} \\
\end{array}$ & $\begin{array}{c}\text { Alternativa } \\
4 \\
\end{array}$ & $\begin{array}{r}\text { Prioridade } \\
\text { média Local }\end{array}$ & & & \\
\hline & & & Alternativa 1 & 0,597 & 0,438 & 0,682 & 0,441 & 0,539 & & & \\
\hline & & & Alternativa 2 & 0,085 & 0,063 & 0,045 & 0,029 & 0,056 & & & \\
\hline & & & Alternativa 3 & 0,199 & 0,313 & 0,227 & 0,441 & 0,295 & & & \\
\hline & & & Alternativa 4 & 0,119 & 0,188 & 0,045 & 0,088 & 0,110 & & & \\
\hline
\end{tabular}

Fonte: Autoria própria (2018)

Legenda:

Alternativa 1 - Gaseificação.

Alternativa 2 - Incineração.

Alternativa 3 - Pirólise.

Alternativa 4-Co-processamento

Assim como na matriz de comparação dos critérios (Quadro 10), nas de comparação das alternativas também foram observados que todos os índices de consistência ficaram abaixo de 0,1.

Durante a reunião com os especialistas, foi possível observar que o critério que mais apresentou dificuldade na determinação das notas para a comparação das alternativas foi o de custo de investimento, o que se deve ao fato da falta de informação precisa com relação a esses valores, principalmente quando se trata de escala industrial. Dessa forma, para a determinação das notas para as alternativas com relação ao custo de investimento na tecnologia foi necessário recorrer à literatura aliada à experiência dos especialistas.

Quando se fala no critério poluentes gerados, considerado como critério mais importante, a alternativa que obteve maior nota foi a pirólise, seguida da gaseificação. Essas alternativas obtiveram maiores notas pois, por serem tecnologias que utilizam pouco ou nenhum oxigênio no seu processo, tem 
chances muito menores de emanarem gases tóxicos quando comparado às outras duas alternativas.

Já quando se fala no critério fatores logísticos, as alternativas coprocessamento e incineração obtiveram as maiores notas. Isso se deve ao fato de existirem unidades de tratamento das alternativas mencionadas próximo à empresa alvo de estudo na pesquisa, o que reduz bastante os possíveis problemas relacionados a fatores logísticos.

Por fim, com as prioridades médias locais calculadas para os critérios e para as alternativas, foi possível encontrar o vetor decisão, mostrado no Quadro 14.

Quadro 14 - Cálculo do vetor decisão

\begin{tabular}{|c|c|c|c|c|c|c|}
\hline \multirow{2}{*}{\begin{tabular}{|c|}
$\begin{array}{c}\text { Critérios/ } \\
\text { Alternativas }\end{array}$ \\
Vetor critérios
\end{tabular}} & \multicolumn{5}{|c|}{ Critério 1 Critério 2 Critério 3 Critério 4 Criterio 5} & \multirow{2}{*}{ Vetor decisão } \\
\hline & 0,489 & 0,174 & 0,213 & 0,075 & 0,049 & \\
\hline Alternativa 1 & 0,306 & 0,269 & 0,097 & 0,125 & 0,539 & 0,253 \\
\hline Alternativa 2 & 0,045 & 0,091 & 0,252 & 0,375 & 0,056 & 0,122 \\
\hline Alternativa 3 & 0,548 & 0,565 & 0,097 & 0,125 & 0,295 & 0,410 \\
\hline Alternativa 4 & 0,101 & 0,075 & 0,555 & 0,375 & 0,110 & 0,214 \\
\hline
\end{tabular}

Fonte: Autoria própria (2018)

Desta forma, a partir dos dados obtidos pelo Quadro 14, é possível ordenar as alternativas da seguinte forma, onde a primeira colocada foi a que obteve melhor pontuação pelos especialistas, sendo assim a mais indicada como destinação:

10. Pirólise $(41,0 \%)$

2‥ Gaseificação (25,3\%)

3‥ Co-processamento $(21,4 \%)$

4․ Incineração $(12,2 \%)$

Como é possível observar, a alternativa que obteve maior nota foi a Pirólise. A tecnologia de Pirólise possui diversas vantagens quando comparada às outras alternativas. O fato de as reações na Pirólise ocorrerem de forma que praticamente não há geração de gases tóxicos faz com que ela obtenha notas muito maiores frente às outras alternativas no quesito "Poluentes gerados", o que impactou bastante no resultado final. Além disso, de acordo com Marchezetti et al. (2011) o custo com a implementação da tecnologia se apresenta como o mais baixo.

Porém, o método ainda precisa ser mais estudado em escala industrial para avaliar a viabilidade financeira da implementação da tecnologia na empresa. Desta forma, é aconselhável a realização de um estudo de viabilidade técnica e financeira anteriormente à aplicação da solução. 


\section{CONCLUSÕES}

Muitas vezes nos deparamos com problemas onde a decisão a ser tomada depende de muitos fatores, inclusive humanos, o que torna a tomada de decisão complicada. Nesse contexto, a realização do trabalho possibilitou o conhecimento mais aprofundado de uma técnica que visa exatamente aliar fatores não exatos, como a opinião das pessoas, à uma técnica matemática.

Durante a realização do trabalho, principalmente na etapa de revisão bibliográfica, foi observado uma falta de material disponível quando se restringia a busca à área industrial. Nesse contexto o sucesso do presente trabalho se apresenta como um incentivo à utilização do método AHP na indústria.

O uso da metodologia de AHP se mostrou adequada para ser utilizada em situações complexas onde a experiência e conhecimento das pessoas precisa ser levado em consideração. Como resultado final a pirólise foi escolhida como melhor alternativa e o resultado obtido foi satisfatório, comprovando que o uso do método AHP para o gerenciamento de resíduos sólidos é eficaz.

Como sugestão para trabalhos futuros:

- Realização de análise mais aprofundada de viabilidade econômica para a implementação de unidade de pirolise na empresa;

- Utilização de outro método Multi-Critério e comparação dos resultados;

- Aplicação do método AHP para outras situações de tomada de decisão na empresa. 


\title{
Application of AHP method to aid in the decision making of best treatment for oil sludge generated by petrochemical industry
}

\begin{abstract}
Economic growth and consequently the increased demand for consumer goods has been generating a growing problem related to solid waste management both in Brazil and worldwide. Allied to this, there is the fact that there are few studies when it comes to industrial solid waste, especially those from the petrochemical industry. This reality motivated this work, whose main objective is to determine the best alternative for the treatment of oily sludge generated by a petrochemical company. For this, the AHP (Analytic Hierarchy Process) multi-criteria analysis method was used, widely used in decision-making situations where the experience of people needs to be taken into account. Thus, to carry out the hierarchical structure of the alternatives and criteria, it was necessary the presence of environmental specialists of the company. The hierarchization of the treatment alternatives addressed in the study produced as the final result the pyrolysys as the most appropriate alternative to the problem in question, with $41 \%$ preference over the other alternatives mentioned in the study. With the results obtained by the method comparison matrices, it was possible to conclude that there is an increasing concern by companies regarding waste management and its possible impacts on the environment. Another conclusion, however, is that in the Brazil there is still a need to grow with regarding to research and development in the area of industrial solid waste management, so that there are more treatment options and that they are more accessible.
\end{abstract}

KEYWORDS: AHP Method. Solid Waste. Oily Sludge. Treatment Technology 


\section{REFERÊNCIAS}

ACHILLAS, C.; MOUSSIOPOULOS, N.; KARAGIANNIDIS, A.; BANIAS, G.; PERKOULIDIS, G. The use of multi-criteria decision analysis to tackle waste management problems: A literature review. Waste Management and Research, v.31, n.2, p.115-129, 2013. crossref

ARENA, U. Process and technological aspects of municipal solid waste gasification. A review. Waste Management, v.32, n.4, p. 625-639, 2012. crossref

BURKE, C. S.; SALAS, E.; SMITH-JENTSCH, K.; ROSEN, M. A. Measuring Macrocognition in Teams: Some Insights for Navigating the Complexities. In E. S. Patterson, and J. E. Miller (Eds.) Macrocognition Metrics and Scenarios: Design and Evaluation for Real-World Teams. Ashgate: Burlington, VT, 2012.

CERQUEIRA, V. S. (2011). Biorremediação de borra oleosa proveniente de indústria Petroquímica em microcosmos. 2011. 213 f. (Doutorado em Microbiologia Agrícola e do Ambiente) - Programa de Pós-Graduação em Microbiologia Agrícola e do Ambiente, Porto Alegre, 2011.

ENGINEERS, N. B. C. Handbook on Recycling and Disposal of Hospital Waste Municipal Solid Waste Biomedical Waste Plastic Waste. NIIR PROJECT CONSULTANCY SERVICES, 1999.

FRASSOM, A. C. Escolha de Alternativa Tecnológica para Tratamento e destino final de Lodo Gerado no Tratamento de Efluentes Líquidos de Agroindústrias com base no Método AHP. 2011. 86 f. Dissertação (Mestrado em Engenharia de Edificações e Saneamento) - Programa de Pós em Engenharia de Edificações e Saneamento, Universidade Estadual de Londrina, Londrina, 2011.

GARTNER, I. R. Avaliação ambiental de projetos em bancos de desenvolvimento nacionais e multilaterais: evidências e propostas. Brasília: Editora Universa, 2001.

GOULART C. L. M.; LANGE, L. C.; COELHO, H. M. Multi-criteria decision making to support waste management: A critical review of current practices and methods. Waste Management \& Research, v.35, n.1, p.3-28, 2017. crossref

HUANG, I. B.; KEISLER, J.; LINKOV, I. Multi-criteria decision analysis in environmental sciences: Ten years of applications and trends. Science of the Total Environment, v.409, n.19, p.3578-3594, 2011. crossref

ISLAM, B. Petroleum sludge, its treatment and disposal: A review. International Journal of Chemical Sciences, v.13, n.4, p.1584-1602, 2015.

IPCC (2013). Climate Change 2013: The Physical Science Basis. Contribution of Working Group I to the Fifth Assessment Report of the Intergovernmental Panel on Climate Change. Stocker, T.F., D. Qin, G.-K. Plattner et al. (Eds.). Cambridge, United Kingdom and New York, NY, U.S. http://www.ipcc.ch/report/ar5/wg1/ 
MARCHEZETTI, A. L.; KAVISKI, E.; BRAGA, M. C. B. Aplicação do método AHP para a hierarquização das alternativas de tratamento de resíduos sólidos domiciliares. Ambiente Construído, v.11, n.2, p.173-187, 2011.

crossref

MACHADO, C. F. Incineração: uma análise do tratamento térmico dos resíduos sólidos urbanos de Bauru/SP. 2015. 97 f. (Especialização em Engenharia ambiental) - Programa de Pós-Graduação em Engenharia Ambiental, Universidade Federal do Rio de Janeiro Rio de Janeiro, 2015.

MARTINS, M. C. Método de análise hierárquica aplicado ao planejamento de uma rede óptica passiva. 2015. 83 f. (Graduação em Engenharia Elétrica) Departamento de Engenharia Elétrica e Computação, Universidade de São Paulo, São Paulo, 2015.

MORRIS, M.; WALDHEIM, L. Energy recovery from solid waste fuels using advanced gasification technology. Waste Management, v.18, n. 8, 557-564, 1998. crossref

MORGADO, T. C.; FERREIRA, O. M. Incineração de Resíduos Sólidos Urbanos, Aproveitamento na Cogeração de Energia. Estudo para a Região Metropolitana de Goiânia. Revista da Engenharia Ambiental da Universidade Católica de Goiás, Goiânia, GO, v. 2, p.1-18, 2006.

MILANEZ, B. Co-Incineração De Resíduos Industriais em Fornos de Cimento: Problemas e Desafios. In. ENCONTRO NACIONAL SOBRE GESTÃO EMPRESARIAL E MEIO AMBIENTE, 21, 2007, Curitiba. Anais Biologia \& Ciências. Curitiba: ENGEMA, 2007.

NEGRÃO, M.; ALMEIDA, A. Incineração de resíduos: contexto e riscos associados. Paris: Fundação France Libertés, 15 jul. 2010. Disponível em: http://incineradornao.net/2010/07/incineracao-de-residuos-contexto-e-riscosassociados/. Acesso em: 28 out. 2018.

OLIVEIRA, C. A.; BELDERRAIN, M. C. N. Considerações sobre a Obtenção de Vetores de prioridade no AHP. In: ENCUENTRO NACIONAL DE DOCENTES, 1, 2008, Posadas. Anales do EPIO. Posadas: END, 2008.

PAIXÃO, J. F. Diagnóstico dos Resíduos Sólidos Urbanos. Governo Federal Secretaria de Assuntos Estratégicos, 66. 2012. Disponível em: http://www.ipea.gov.br/agencia/images/stories/PDFs/relatoriopesquisa/121009 _relatorio_residuos_solidos_urbanos.pdf. Acesso em: 31 out. 2018.

ROCHA, S. D. F.; LINS, V. F. C.; SANTO, B. C. E. Aspects of waste co-processing in clinker kilns. Engenharia Sanitaria e Ambiental, v.16, n.1, p.1-10, 2011. crossref

SAATY, T. L. Decision making with the analytic hierarchy process. International Journal of Services Sciences, v.1, n.1, p. 83-98, 2008. crossref

SAATY, R. W. The analytic hierarchy process-what it is and how it is used. Mathematical Modelling, v.9, n.5, p.161-176, 1987. crossref 
SAATY, T. L. How to make a decision: The analytic hierarchy process. European Journal of Operational Research, v.48, n.1, p.9-26, 1990. crossref

SANTAELLA, S. T.; BRITO, A. E. R. M.; COSTA, F. A. P.; CASTILHO, N. M.; MIO, G. P.; FILHO, E. F.; SALEK, J. M. Resíduos sólidos e a atual política ambiental brasileira. Fortaleza: UFC. Labomar/Nave, 2014.

SANTOS, P. C. Recentes impactos da Indústria Petroquímica sobre o parque de refino. 2008. 144 f. (Mestrado em Tecnologia de Processos Químicos e Bioquímicos) - Pós-Graduação em Tecnologia de Processos Químicos e Bioquímicos), Universidade Federal do Rio de Janeiro, Rio de Janeiro, 2008.

SONI, V.; NAIK, V. Gasification-A Process for Energy Recovery and Disposal of Municipal Solid Waste. American Journal of Modern Energy, v.2, n.6, p.38-42, 2016.

SOUTO, L. B. Modelo de apoio multicritério à decisão aplicado à destinação de resíduos sólidos industriais. 2014. 188 f. (Mestrado em Engenharia de Produção) - Mestrado profissional em Produção, Instituto Tecnológico de Aeronáutica, São José dos Campos, 2014.

TORRES, E. M. M. The evolution of the brazilian petrochemical industry. Química Nova, v. 20, n. SPE, p. 49-54, 1997. crossref

TOCCHETTO, M. R. L. Gerenciamento de Resíduos Sólidos Industriais. 2005. 97 f. (Graduação em Química Industrial) - Departamento de Química, Universidade Federal de Santa Maria, Santa Maria, 2005.

WILSON et al., Global Waste Management Outlook 2015. Ed. Viena: Tara Cannon, 2015.

ZIGLIO, L. Industrial Solid Waste Management in Brazil and the Basel Convention. Novos Estudos Jurídicos, v. 19, n.2, 585, 2014. crossref

ARAUJO, W.C. et al. Aplicação do método AHP para auxílio à tomada de decisão do melhor tratamento para a borra oleosa gerada na indústria Petroquímica. R. Gest. Industr., Ponta Grossa, v. 16, n. 4, p. 29-56, Out./Dez. 2020. Disponível em: https://periodicos.utfpr.edu.br/revistagi

Correspondência:

Wanderbeg Correia de Araujo

Universidade Federal da Bahia (UFBA), Salvador, Bahia, Brasil

Direito autoral: Este artigo está licenciado sob os termos da Licença Creative Commons-Atribuição 4.0

Internacional. 
APÊNDICE

\section{APÊNDICE 1 - QUESTIONÁRIO DA IMPORTÂNCIA DOS CRITÉRIOS}

\begin{tabular}{|c|c|c|c|c|c|c|c|c|c|}
\hline Critério 1 & \multicolumn{3}{|c|}{ Importância } & Critério 2 & Critério 2 & \multicolumn{3}{|c|}{ Importância } & Critério 4 \\
\hline $\begin{array}{c}\text { Poluentes gerados } \\
\text { Residuos, efluente } \\
\text { emissão } \\
\text { atmosferica) }\end{array}$ & $\begin{array}{l}\square \\
\square \\
\square \\
\square \\
\square\end{array}$ & $\begin{array}{c}\text { Igual } \\
\text { Moderada } \\
\text { Forte } \\
\text { Muito forte } \\
\text { Extrema }\end{array}$ & $\begin{array}{l}\square \\
\square \\
\square \\
\square \\
\square\end{array}$ & $\begin{array}{c}\text { Custo de } \\
\text { investimento } \\
\text { na tecnologia }\end{array}$ & $\begin{array}{c}\text { Custo de } \\
\text { investimento } \\
\text { na tecnologia }\end{array}$ & $\begin{array}{l}\square \\
\square \\
\square \\
\square \\
\square\end{array}$ & $\begin{array}{c}\text { Igual } \\
\text { Moderada } \\
\text { Forte } \\
\text { Muito forte } \\
\text { Extrema }\end{array}$ & $\begin{array}{l}\square \\
\square \\
\square \\
\square \\
\square\end{array}$ & $\begin{array}{c}\text { Fator } \\
\text { Logistico }\end{array}$ \\
\hline Critério 1 & & Importância & & Critério 3 & Critério 2 & & Importância & & Critério 5 \\
\hline $\begin{array}{c}\text { Poluentes gerados } \\
\text { Residuos, efluente } \\
\text { emissão } \\
\text { atmosferica) }\end{array}$ & $\begin{array}{l}\square \\
\square \\
\square \\
\square \\
\square\end{array}$ & $\begin{array}{l}\text { Igual } \\
\text { Moderada } \\
\text { Forte } \\
\text { Muito forte } \\
\text { Extrema }\end{array}$ & $\begin{array}{l}\square \\
\square \\
\square \\
\square \\
\square\end{array}$ & $\begin{array}{c}\text { Custo com o } \\
\text { tratamento }\end{array}$ & $\begin{array}{c}\text { Custo de } \\
\text { investimento } \\
\text { na tecnologia }\end{array}$ & $\begin{array}{l}\square \\
\square \\
\square \\
\square \\
\square\end{array}$ & $\begin{array}{l}\text { Igual } \\
\text { Moderada } \\
\text { Forte } \\
\text { Muito forte } \\
\text { Extrema }\end{array}$ & $\begin{array}{l}\square \\
\square \\
\square \\
\square \\
\square\end{array}$ & $\begin{array}{c}\text { Aproveitame } \\
\text { nto } \\
\text { energético }\end{array}$ \\
\hline Critério 1 & & Importância & & Critério 4 & Critério 3 & & Importância & & Critério 4 \\
\hline $\begin{array}{c}\text { Poluentes gerados } \\
\text { Residuos, efluente } \\
\text { emissão } \\
\text { atmosferica) }\end{array}$ & $\begin{array}{l}\square \\
\square \\
\square \\
\square \\
\square\end{array}$ & $\begin{array}{l}\text { Igual } \\
\text { Moderada } \\
\text { Forte } \\
\text { Muito forte } \\
\text { Extrema }\end{array}$ & $\begin{array}{l}\square \\
\square \\
\square \\
\square \\
\square\end{array}$ & $\begin{array}{c}\text { Fator } \\
\text { Logistico }\end{array}$ & $\begin{array}{l}\text { Custo com o } \\
\text { tratamento }\end{array}$ & $\begin{array}{l}\square \\
\square \\
\square \\
\square \\
\square\end{array}$ & $\begin{array}{l}\text { Igual } \\
\text { Moderada } \\
\text { Forte } \\
\text { Muito forte } \\
\text { Extrema }\end{array}$ & $\begin{array}{l}\square \\
\square \\
\square \\
\square \\
\square\end{array}$ & $\begin{array}{c}\text { Fator } \\
\text { Logistico }\end{array}$ \\
\hline Critério 1 & & Importância & & Critério 5 & Critério 3 & & Importância & & Critério 5 \\
\hline $\begin{array}{c}\text { Poluentes gerados } \\
\text { Residuos, efluente } \\
\text { emissão } \\
\text { atmosferica) }\end{array}$ & $\begin{array}{l}\square \\
\square \\
\square \\
\square \\
\square\end{array}$ & $\begin{array}{l}\text { Igual } \\
\text { Moderada } \\
\text { Forte } \\
\text { Muito forte } \\
\text { Extrema } \\
\end{array}$ & $\begin{array}{l}\square \\
\square \\
\square \\
\square \\
\square\end{array}$ & $\begin{array}{l}\text { Aproveitamen } \\
\text { to energético }\end{array}$ & $\begin{array}{c}\text { Custo com o } \\
\text { tratamento }\end{array}$ & $\begin{array}{l}\square \\
\square \\
\square \\
\square \\
\square\end{array}$ & $\begin{array}{l}\text { Igual } \\
\text { Moderada } \\
\text { Forte } \\
\text { Muito forte } \\
\text { Extrema } \\
\end{array}$ & $\begin{array}{l}\square \\
\square \\
\square \\
\square \\
\square\end{array}$ & $\begin{array}{c}\text { Aproveitame } \\
\text { nto } \\
\text { energético }\end{array}$ \\
\hline Critério 2 & & Importância & & Critério 3 & Critério 4 & & Importância & & Critério 5 \\
\hline $\begin{array}{l}\text { Custo de } \\
\text { investimento na } \\
\text { tecnologia }\end{array}$ & $\begin{array}{l}\square \\
\square \\
\square \\
\square \\
\square\end{array}$ & $\begin{array}{l}\text { Igual } \\
\text { Moderada } \\
\text { Forte } \\
\text { Muito forte } \\
\text { Extrema }\end{array}$ & $\begin{array}{l}\square \\
\square \\
\square \\
\square \\
\square\end{array}$ & $\begin{array}{c}\text { Custo com o } \\
\text { tratamento }\end{array}$ & $\begin{array}{c}\text { Fator } \\
\text { Logistico }\end{array}$ & $\begin{array}{l}\square \\
\square \\
\square \\
\square \\
\square\end{array}$ & $\begin{array}{l}\text { Igual } \\
\text { Moderada } \\
\text { Forte } \\
\text { Muito forte } \\
\text { Extrema }\end{array}$ & $\begin{array}{l}\square \\
\square \\
\square \\
\square \\
\square\end{array}$ & $\begin{array}{c}\text { Aproveitame } \\
\text { nto } \\
\text { energético }\end{array}$ \\
\hline
\end{tabular}




\begin{tabular}{|c|c|c|c|c|c|c|c|c|c|c|c|c|c|c|}
\hline \multicolumn{5}{|c|}{$\begin{array}{l}\text { Critério 1: Poluentes gerados (Residuos, efluente, emissão } \\
\text { atmosferica) }\end{array}$} & \multicolumn{5}{|c|}{$\begin{array}{l}\text { Critério 1: Poluentes gerados (Residuos, efluente, emissão } \\
\text { atmosferica) }\end{array}$} & \multicolumn{5}{|c|}{$\begin{array}{l}\text { Critério 1: Poluentes gerados (Residuos, efluente, emissão } \\
\text { atmosferica) }\end{array}$} \\
\hline \begin{tabular}{|l|} 
Alternativa 1 \\
\end{tabular} & & Importância & & Alternativa 2 & Alternativa 1 & & Importância & & Alternativa 3 & Alternativa 1 & & Importância & & Alternativa 4 \\
\hline & $\begin{array}{l}\square \\
\square \\
\square \\
\square \\
\square\end{array}$ & $\begin{array}{c}\text { Igual } \\
\text { Moderada } \\
\text { Forte } \\
\text { Muito forte } \\
\text { Extrema }\end{array}$ & $\begin{array}{l}\square \\
\square \\
\square \\
\square \\
\square\end{array}$ & & & $\begin{array}{l} \\
\square \\
\square \\
\square \\
\square\end{array}$ & $\begin{array}{c}\text { Igual } \\
\text { Moderada } \\
\text { Forte } \\
\text { Muito forte } \\
\text { Extrema }\end{array}$ & $\begin{array}{l}\square \\
\square \\
\square \\
\square \\
\square\end{array}$ & & & $\begin{array}{l}\square \\
\square \\
\square \\
\square \\
\square\end{array}$ & $\begin{array}{c}\text { Igual } \\
\text { Moderada } \\
\text { Forte } \\
\text { Muito forte } \\
\text { Extrema }\end{array}$ & $\begin{array}{l}\square \\
\square \\
\square \\
\square \\
\square\end{array}$ & \\
\hline \multicolumn{5}{|c|}{ Critério 2: Custo de investimento na tecnologia } & \multicolumn{5}{|c|}{ Critério 2: Custo de investimento na tecnologia } & \multicolumn{5}{|c|}{ Critério 2: Custo de investimento na tecnologia } \\
\hline \begin{tabular}{|l|} 
Alternativa 1 \\
\end{tabular} & & Importância & & Alternativa 2 & Alternativa 1 & & Importância & & Alternativa 3 & Alternativa 1 & & Importância & & \\
\hline & $\begin{array}{l}\square \\
\square \\
\square \\
\square \\
\square\end{array}$ & $\begin{array}{l}\text { Igual } \\
\text { Moderada } \\
\text { Forte } \\
\text { Muito forte } \\
\text { Extrema } \\
\end{array}$ & $\begin{array}{l}\square \\
\square \\
\square \\
\square \\
\square\end{array}$ & & & $\begin{array}{l} \\
\square \\
\square \\
\square \\
\square\end{array}$ & $\begin{array}{l}\text { Igual } \\
\text { Moderada } \\
\text { Forte } \\
\text { Muito forte } \\
\text { Extrema } \\
\end{array}$ & $\begin{array}{l}\square \\
\square \\
\square \\
\square \\
\square\end{array}$ & & & $\begin{array}{l}\square \\
\square \\
\square \\
\square \\
\square\end{array}$ & $\begin{array}{l}\text { Igual } \\
\text { Moderada } \\
\text { Forte } \\
\text { Muito forte } \\
\text { Extrema }\end{array}$ & $\begin{array}{l}\square \\
\square \\
\square \\
\square \\
\square\end{array}$ & \\
\hline \multicolumn{5}{|c|}{ Critério 3: Custo com o tratamento } & \multicolumn{5}{|c|}{ Critério 3: Custo com o tratamento } & \multicolumn{5}{|c|}{ Critério 3: Custo com 0 tratamento } \\
\hline \begin{tabular}{|l|} 
Alternativa 1 \\
\end{tabular} & & Importância & & Alternativa 2 & Alternativa 1 & & Importância & & Alternativa 3 & Alternativa 1 & & Importância & & \\
\hline & $\begin{array}{l}\square \\
\square \\
\square \\
\square \\
\square\end{array}$ & $\begin{array}{l}\text { Igual } \\
\text { Moderada } \\
\text { Forte } \\
\text { Muito forte } \\
\text { Extrema } \\
\end{array}$ & $\begin{array}{l} \\
\square \\
\square \\
\square \\
\square\end{array}$ & & & $\begin{array}{l}\square \\
\square \\
\square \\
\square \\
\square\end{array}$ & $\begin{array}{l}\text { Igual } \\
\text { Moderada } \\
\text { Forte } \\
\text { Muito forte } \\
\text { Extrema } \\
\end{array}$ & $\begin{array}{l}\square \\
\square \\
\square \\
\square \\
\square\end{array}$ & & & $\begin{array}{l}\square \\
\square \\
\square \\
\square \\
\square\end{array}$ & $\begin{array}{c}\text { Igual } \\
\text { Moderada } \\
\text { Forte } \\
\text { Muito forte } \\
\text { Extrema }\end{array}$ & $\begin{array}{l}\square \\
\square \\
\square \\
\square \\
\square\end{array}$ & \\
\hline \multicolumn{5}{|c|}{\begin{tabular}{|l|} 
Critério 4: Fator logistico \\
\end{tabular}} & \multicolumn{5}{|c|}{ Critério 4: Fator logistico } & \multicolumn{5}{|c|}{ Critério 4: Fator logistico } \\
\hline \begin{tabular}{|l|} 
Alternativa 1 \\
\end{tabular} & & Importância & & Alternativa 2 & Alternativa 1 & & Importância & & Alternativa 3 & Ailternativa 1 & & Importância & & \\
\hline & $\begin{array}{l}\square \\
\square \\
\square \\
\square \\
\square\end{array}$ & $\begin{array}{c}\text { Igual } \\
\text { Moderada } \\
\text { Forte } \\
\text { Muito forte } \\
\text { Extrema }\end{array}$ & $\begin{array}{l}\square \\
\square \\
\square \\
\square \\
\square\end{array}$ & & & $\begin{array}{l}\square \\
\square \\
\square \\
\square \\
\square\end{array}$ & $\begin{array}{l}\text { Igual } \\
\text { Moderada } \\
\text { Forte } \\
\text { Muito forte } \\
\text { Extrema }\end{array}$ & $\begin{array}{l}\square \\
\square \\
\square \\
\square \\
\square\end{array}$ & & & $\begin{array}{l}\square \\
\square \\
\square \\
\square \\
\square\end{array}$ & $\begin{array}{l}\text { Igual } \\
\text { Moderada } \\
\text { Forte } \\
\text { Muito forte } \\
\text { Extrema }\end{array}$ & $\begin{array}{l}\square \\
\square \\
\square \\
\square \\
\square\end{array}$ & \\
\hline \multicolumn{5}{|c|}{ Eitamento energético } & \multicolumn{5}{|c|}{ Critério 5: Aproveitamento energético } & \multicolumn{5}{|c|}{ Critério 5: Aproveitamento energético } \\
\hline \begin{tabular}{|l|} 
Alternativa 1 \\
\end{tabular} & & Importância & & Alternativa 2 & Alternativa 1 & & Importância & & Alternativa 3 & Aliternativa 1 & & Importância & & \\
\hline & $\begin{array}{l}\square \\
\square \\
\square \\
\square \\
\square\end{array}$ & $\begin{array}{c}\text { Igual } \\
\text { Moderada } \\
\text { Forte } \\
\text { Muito forte } \\
\text { Extrema } \\
\end{array}$ & $\begin{array}{l}\square \\
\square \\
\square \\
\square \\
\square\end{array}$ & & & $\begin{array}{l}\square \\
\square \\
\square \\
\square \\
\square\end{array}$ & $\begin{array}{c}\text { Igual } \\
\text { Moderada } \\
\text { Forte } \\
\text { Muito forte } \\
\text { Extrema } \\
\end{array}$ & $\begin{array}{l}\square \\
\square \\
\square \\
\square \\
\square\end{array}$ & & & $\begin{array}{l}\square \\
\square \\
\square \\
\square \\
\square\end{array}$ & $\begin{array}{c}\text { Igual } \\
\text { Moderada } \\
\text { Forte } \\
\text { Muito forte } \\
\text { Extrema } \\
\end{array}$ & $\begin{array}{l}\square \\
\square \\
\square \\
\square \\
\square\end{array}$ & \\
\hline
\end{tabular}

\begin{tabular}{|c|c|c|c|c|c|c|c|c|c|c|c|c|c|c|}
\hline \multicolumn{5}{|c|}{$\begin{array}{l}\text { Critério 1: Poluentes gerados (Residuos, efluente, emissão } \\
\text { atmosferica) }\end{array}$} & \multicolumn{5}{|c|}{$\begin{array}{l}\text { Critério 1: Poluentes gerados (Residuos, efluente, emissão } \\
\text { atmosferica) }\end{array}$} & \multicolumn{5}{|c|}{$\begin{array}{l}\text { Critério 1: Poluentes gerados (Residuos, efluente, emissão } \\
\text { atmosferica) }\end{array}$} \\
\hline \multirow[t]{6}{*}{\begin{tabular}{|l} 
Alternativa 1 \\
\end{tabular}} & \multicolumn{3}{|c|}{ Importância } & \multirow{6}{*}{ Alternativa 3} & \multirow[t]{6}{*}{ Alternativa 1} & \multicolumn{3}{|c|}{ Importância } & \multirow{6}{*}{$e^{\text {Alternativa } 4}$} & \multirow[t]{2}{*}{\begin{tabular}{|l} 
Alternativa 3 \\
\end{tabular}} & \multicolumn{3}{|c|}{ Importância } & \multirow[t]{2}{*}{ Alternativa 4} \\
\hline & $\square$ & Igual & $\square$ & & & $\square$ & Igual & $\square$ & & & $\square$ & Igual & $\square$ & \\
\hline & $\square$ & Moderada & $\square$ & & & $\square$ & Moderada & $\square$ & & & $\square$ & Moderada & $\square$ & \\
\hline & $\square$ & Forte & $\square$ & & & $\square$ & Forte & $\square$ & & & $\square$ & Forte & $\square$ & \\
\hline & $\square$ & Muito forte & $\square$ & & & $\square$ & Muito forte & $\square$ & & & $\square$ & Muito forte & $\square$ & \\
\hline & & Extrema & $\square$ & & & & Extrema & & & & $\square$ & Extrema & & \\
\hline \multicolumn{5}{|c|}{ Critério 2: Custo de investimento na tecnologia } & \multicolumn{5}{|c|}{ Critério 2: Custo de investimento na tecnologia } & \multicolumn{5}{|c|}{ Critério 2: Custo de investimento na tecnologia } \\
\hline \multirow[t]{6}{*}{\begin{tabular}{|l} 
Alternativa 1 \\
\end{tabular}} & \multicolumn{3}{|c|}{ Importância } & Alternativa 3 & \multirow{6}{*}{ Alternativa 1} & \multicolumn{3}{|c|}{ Importância } & Alten & \multirow{6}{*}{ Alternativa 3} & \multicolumn{3}{|c|}{ Importância } & \\
\hline & $\square$ & Igual & $\square$ & & & $\square$ & Igual & $\square$ & & & $\square$ & Igual & $\square$ & \\
\hline & $\square$ & Moderada & $\square$ & & & $\square$ & Moderada & $\square$ & & & $\square$ & Moderada & $\square$ & \\
\hline & $\square$ & Forte & $\square$ & & & $\square$ & Forte & $\square$ & & & $\square$ & Forte & $\square$ & \\
\hline & $\square$ & Muito forte & $\square$ & & & $\square$ & Muito forte & $\square$ & & & $\square$ & Muito forte & $\square$ & \\
\hline & $\square$ & Extrema & $\square$ & & & $\square$ & Extrema & $\square$ & & & $\square$ & Extrema & $\square$ & \\
\hline \multicolumn{5}{|c|}{ Critério 3: Custo com o tratamento } & \multicolumn{5}{|c|}{ Critério 3: Custo com o tratamento } & \multicolumn{5}{|c|}{ Critério 3: Custo com o tratamento } \\
\hline \multirow{6}{*}{\begin{tabular}{|l|} 
Alternativa 1 \\
\end{tabular}} & & Importância & & Alternativa 3 & Alternativa 1 & & Importância & & & Alternativa 3 & & Importância & & \\
\hline & $\square$ & Igual & $\square$ & & & $\square$ & Igual & $\square$ & & & $\square$ & Igual & $\square$ & \\
\hline & $\square$ & Moderada & $\square$ & & & $\square$ & Moderada & $\square$ & & & $\square$ & Moderada & $\square$ & \\
\hline & $\square$ & Forte & $\square$ & & & $\square$ & Forte & $\square$ & & & $\square$ & Forte & $\square$ & \\
\hline & $\square$ & Muito forte & $\square$ & & & $\square$ & Muito forte & $\square$ & & & $\square$ & Muito forte & $\square$ & \\
\hline & $\square$ & Extrema & $\square$ & & & $\square$ & Extrema & $\square$ & & & $\square$ & Extrema & $\square$ & \\
\hline Critério 4: $\mathrm{Fa}$ & logis & & & & Critério 4: Fat & $\operatorname{logi}$ & & & & Critério 4: Fat & logist & & & \\
\hline Alternativa 1 & & Importância & & Alternativa 3 & Alternativa 1 & & Importância & & Alternativa 4 & Alternativa 3 & & Importância & & \\
\hline & $\square$ & Igual & $\square$ & & & $\square$ & Igual & $\square$ & & & $\square$ & Igual & $\square$ & \\
\hline & $\square$ & Moderada & $\square$ & & & $\square$ & Moderada & $\square$ & & & $\square$ & Moderada & $\square$ & \\
\hline & $\square$ & Forte & $\square$ & & & $\square$ & Forte & $\square$ & & & $\square$ & Forte & $\square$ & \\
\hline & $\square$ & Muito forte & $\square$ & & & $\square$ & Muito forte & $\square$ & & & $\square$ & Muito forte & $\square$ & \\
\hline & $\square$ & Extrema & $\square$ & & & $\square$ & Extrema & $\square$ & & & $\square$ & Extrema & $\square$ & \\
\hline Critério 5: $\mathrm{Ap}$ & veitan & nto energético & & & Critério 5: Apr & veitar & nto energético & & & Critério 5: Ap & veitam & to energético & & \\
\hline \begin{tabular}{|l|} 
Alternativa 1 \\
\end{tabular} & & Importância & & Alternativa 3 & \begin{tabular}{|l|} 
Alternativa 1 \\
\end{tabular} & & Importância & & \begin{tabular}{|l|l|l|l} 
Alternativa 4 \\
\end{tabular} & Alternativa 3 & & Importância & & va 4 \\
\hline & $\square$ & Igual & $\square$ & & & $\square$ & Igual & $\square$ & & & $\square$ & Igual & $\square$ & \\
\hline & $\square$ & Moderada & $\square$ & & & $\square$ & Moderada & $\square$ & & & $\square$ & Moderada & $\square$ & \\
\hline & $\square$ & Forte & $\square$ & & & $\square$ & Forte & $\square$ & & & $\square$ & Forte & $\square$ & \\
\hline & $\square$ & Muito forte & $\square$ & & & $\square$ & Muito forte & $\square$ & & & $\square$ & Muito forte & $\square$ & \\
\hline
\end{tabular}

